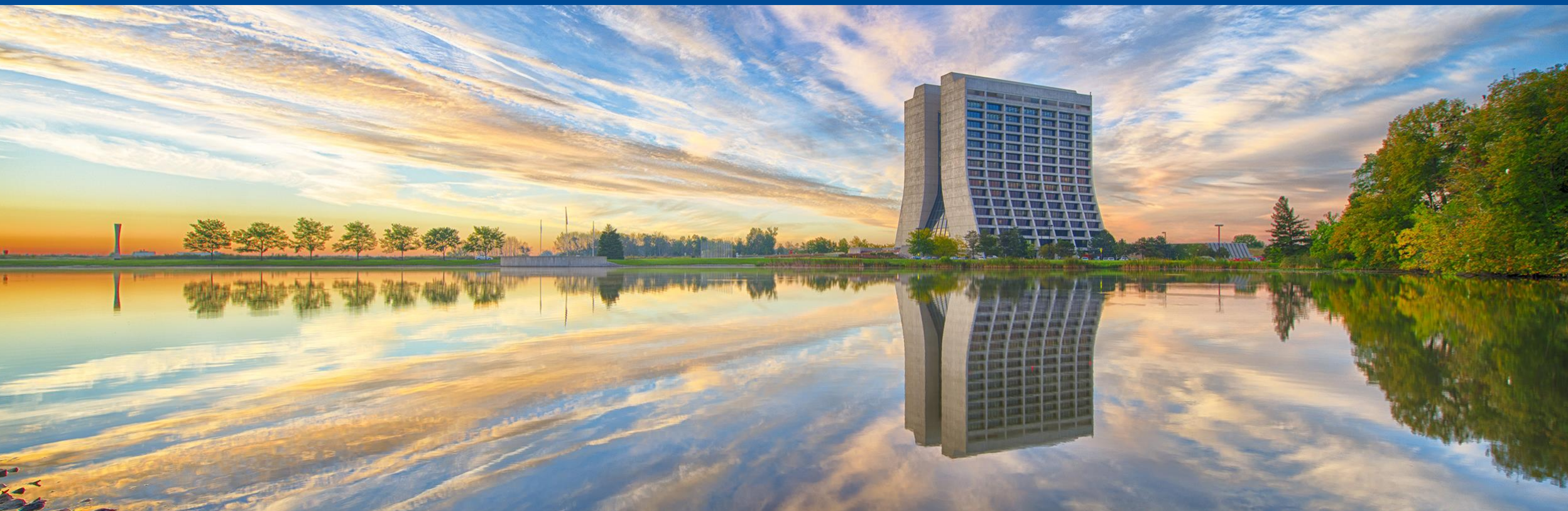

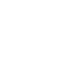

\title{
Thermal contact resistance
}

\section{R.C. Dhuley}

CSA Short Course: Property and Cooler Considerations for Cryogenic Systems

Sunday, July 21 2019; CEC-ICMC 2019 at Hartford CT

This manuscript has been authored by Fermi Research Alliance, LLC under Contract No. DE-AC02-07CH11359 with the U.S. Department of Energy, Office of Science, Office of High Energy Physics. 


\section{Technical importance in cryogenics}

Any cryogen-free system or a system seeking to be cryogen-free will encounter thermal contact resistance

- Sub-Kelvin experiments coupled to ADRs, dilution refrigerators, etc.

- Bath cooled systems seeking cryogen-independence via conductive coupling to cryocoolers

Undesired consequences of large thermal contact resistance:

- Long cooldown times

- Poor thermal equilibrium between experiment and cooler even when heats leaks are small

- Large sample-cooler temperature jump during operation (reduction in the range of operating temperatures)

- Each of the above issue will worsen with decreasing temperature!

Complexities:

- No unified or simple models: too many governing parameters

- Difficult experimental characterization 


\section{Outline and course objectives}

Objectives: To understand the complexities of the problem, familiarize with existing theory to obtain rough estimates, learn how to characterize low temperature thermal contacts.

Outline:

- Origins and mechanisms

- Theoretical models for metallic contacts

- 'macroscopic' constriction resistance

- 'microscopic' boundary resistance

- Characteristics of contact resistance at low temperatures

- Measurement techniques

- Contact resistance R\&D at Fermilab

- SuperCDMS SNOLAB sub-Kelvin cryostat

- Conduction cooling of an SRF niobium cavity

- Examples of data from the literature 


\section{Origins}

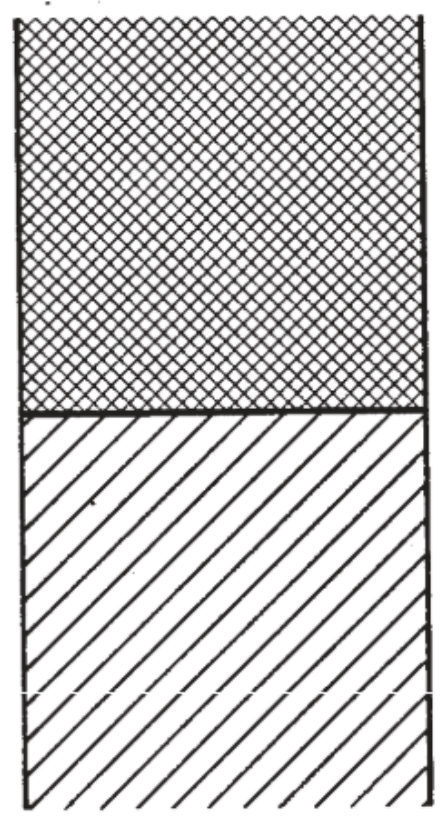

a)

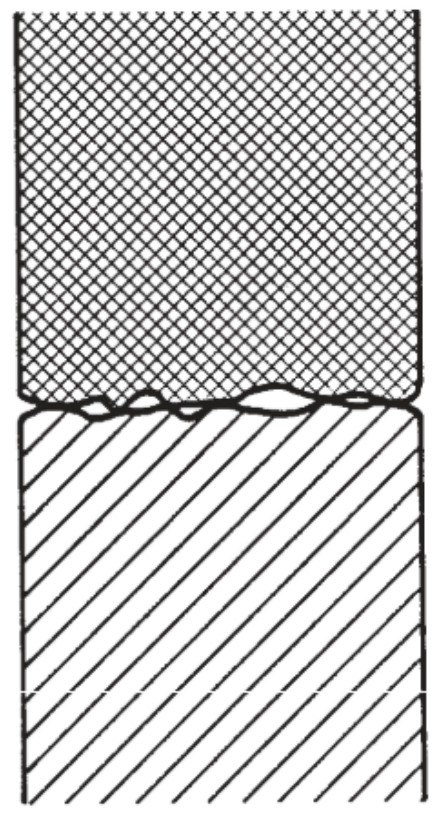

b)

Reduction in heat transfer area

- surface "waviness", microscopic asperities (roughness)

Oxide surface layer (metals)

Surface films, adsorbed gases

Differential thermal contraction

(cryogenic case)

Ref: Van Sciver, Nellis, Pfotenhauer

The actual physical boundary

(carrier reflection, scattering) 


\section{Contact heat transfer mechanisms}

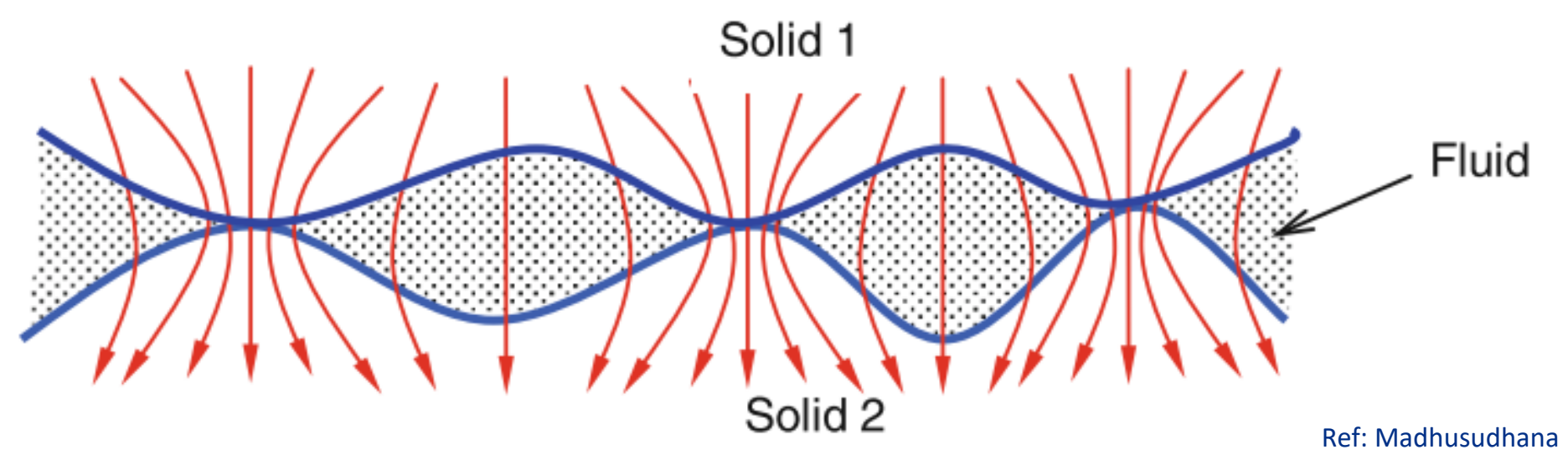

- Conduction through actual solid-solid contact spots (spot or constriction resistance)

- important for cryogenic applications

- Conduction through interstitial medium, example air (gap resistance)

- neglected if fluid is absent (eg. vacuum in cryogenic systems)

- Radiation

- small unless $T$ or $\Delta T$ are is large (not significant at low $T$ ) 


\section{Spot resistance, analyses}

Heat flow analysis (thermal model)

- constriction resistance due to "thinning" of heat flow lines

- boundary reflection of heat carriers (electrons, phonons)

- determines the basic premise of contact resistance

Surface texture analysis (geometrical model)

- surface roughness, slope of as valleys and peaks

- determines number and size of contacting asperities

Asperity deformation analysis (mechanical model)

- Surface microhardness, elastic modulus, applied pressure/force

- determines the area of 'real' or physical contact (the surface area available for heat transfer) 


\section{Thermal analysis: macroscopic vs. microscopic}

Differentiated based on spot "Knudsen" number

$$
K n=\frac{\text { mean free path }, l}{\text { constriction size, } a}
$$

(equivalent of continuum and molecular flow regimes of gases)

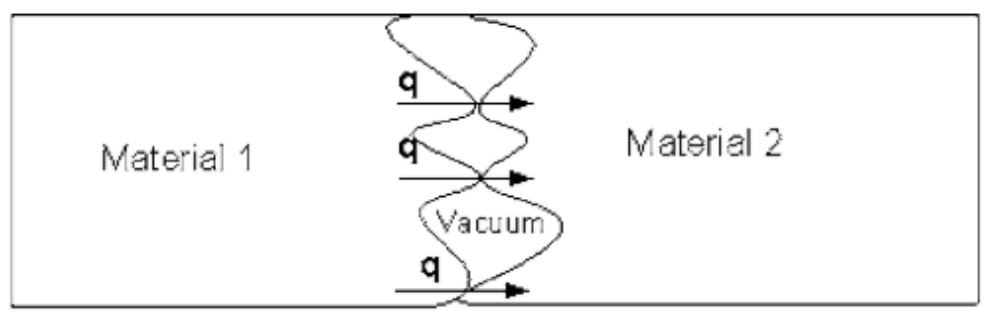

(a)

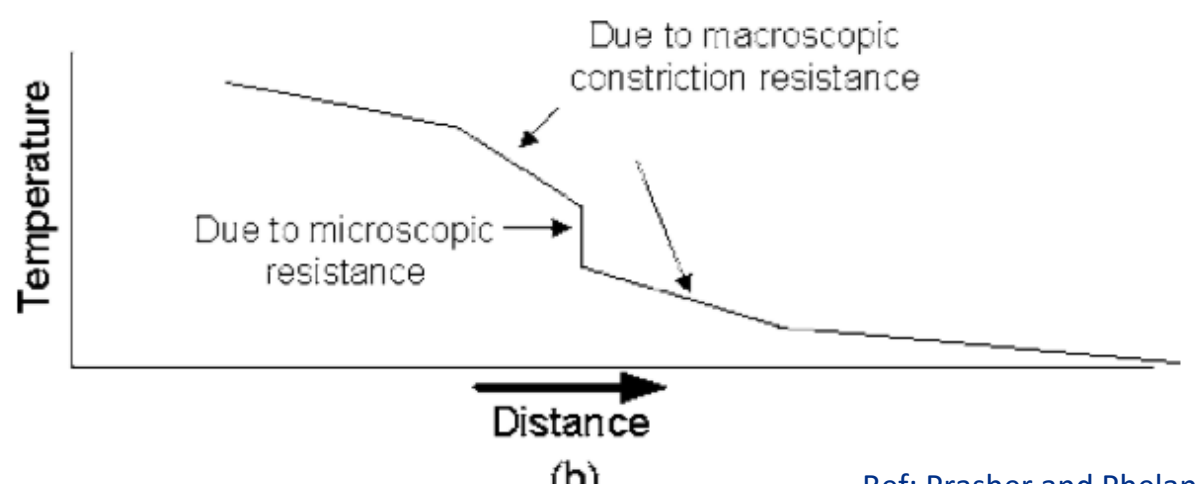

(b)

Major influencers

I: temperature and purity of metals (especially cryogenic conditions)

a: surface finish/roughness, machining processes 


\section{Thermal analysis: macroscopic vs. microscopic}

Constriction resistance

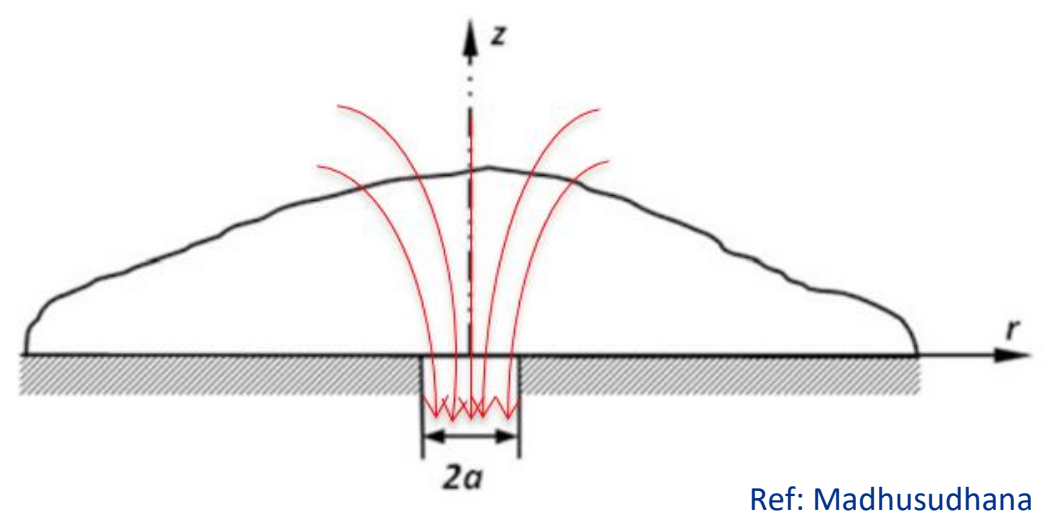

$l<<a$

- diffusion limited thermal transport

- macroscopic component dominates
Boundary resistance

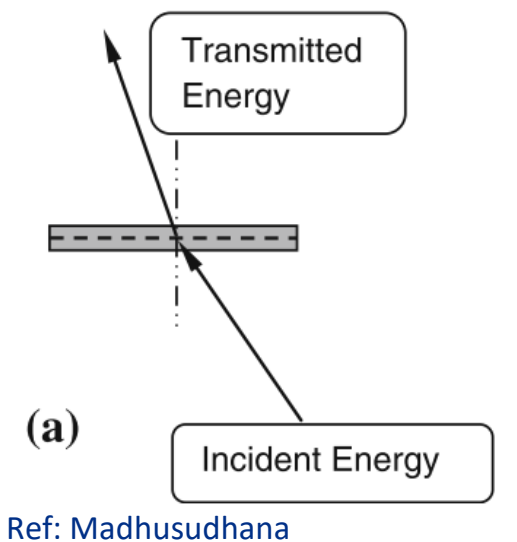

(b)

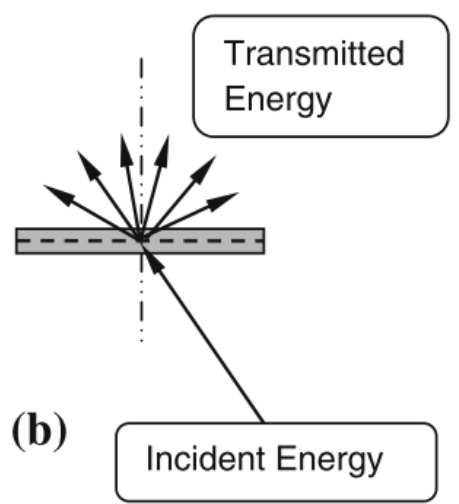

Ref: Madhusudhana

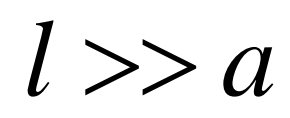

- ballistic/boundary scattering effects

- microscopic component dominates

$l \sim a$ : both effects important 


\section{Thermal analysis of a spot: macroscopic}

- Macroscopic spot resistance $(l<<a)$ : "bulk" thermal conductivity holds valid at the spot (diffusion regime)

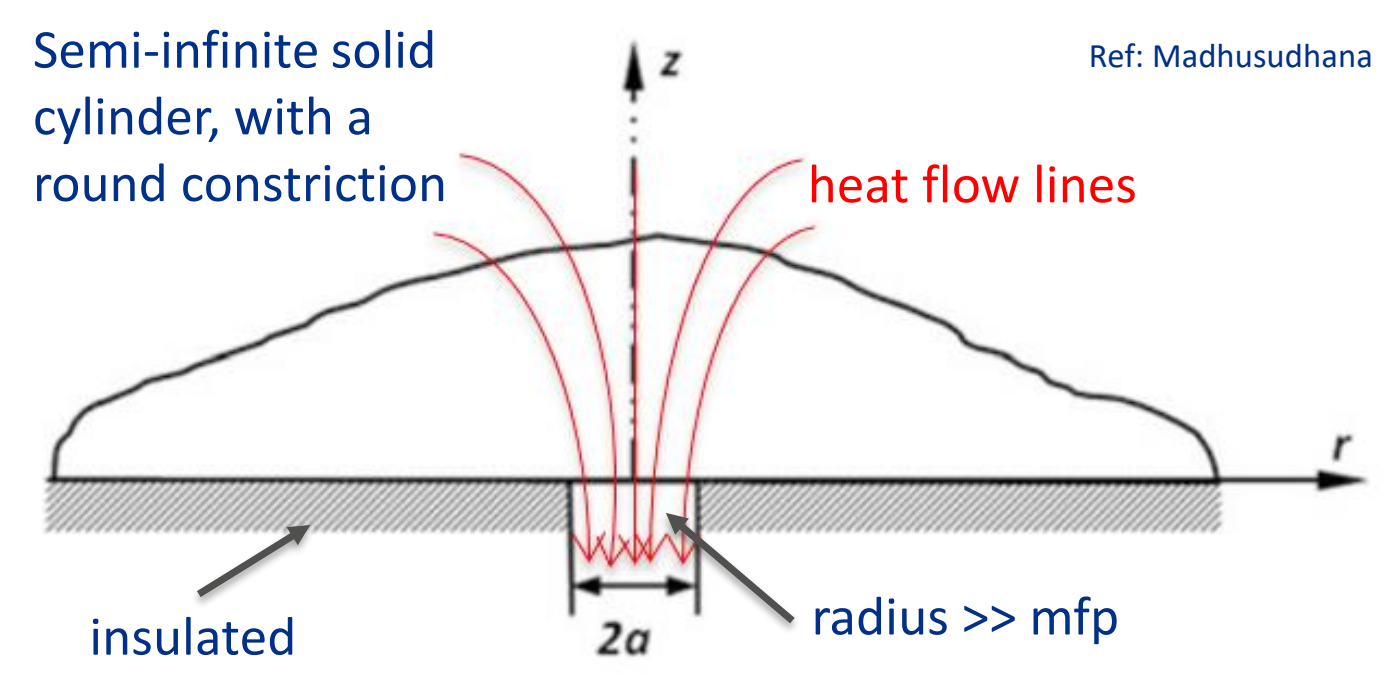

Analytical solution is obtained by solving the steady state heat diffusion in cylindrical coordinates

$$
\frac{\partial^{2} T}{\partial r^{2}}+\frac{1}{r} \frac{\partial T}{\partial r}+\frac{\partial^{2} T}{\partial z^{2}}=0
$$

- Result (See textbook by C. V. Madhusudhana for analytical solution steps):

$$
\begin{aligned}
& R_{\text {macro,spot }}=\frac{1}{4 a k}=\frac{0.25}{a k} \quad \begin{array}{l}
\text { Spot at uniform } \\
\text { temperature }
\end{array} \\
& R_{\text {macro,spot }}=\frac{8}{3 \pi a^{2} k}=\frac{0.27}{a k} \quad \begin{array}{l}
\text { Spot with uniform } \\
\text { heat flux }
\end{array}
\end{aligned}
$$

- Unit is K/W

- Spot condition changes the solution by $8 \%$ (often negligible in practice) 


\section{Thermal analysis of spots in parallel, joints}

- Bounded spot

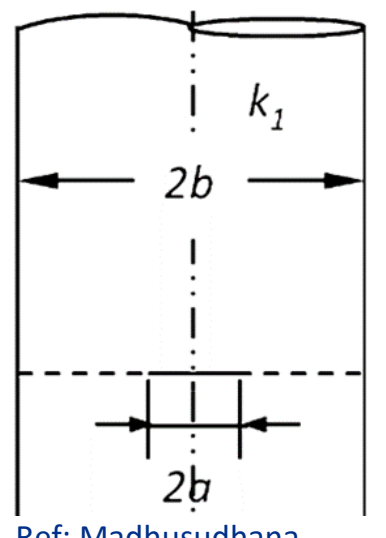

Ref: Madhusudhana
$R_{C}=\frac{\psi(a / b)}{4 a k}$

- $\psi(a / b)$ is constriction alleviation factor $(<1)$

- Usable form is given later

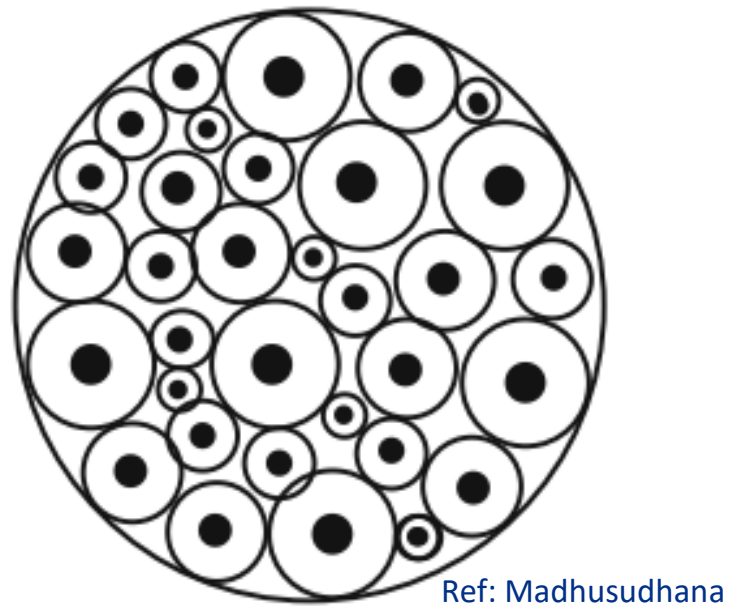

(idealized representation of contact plane)
- Bounded joint

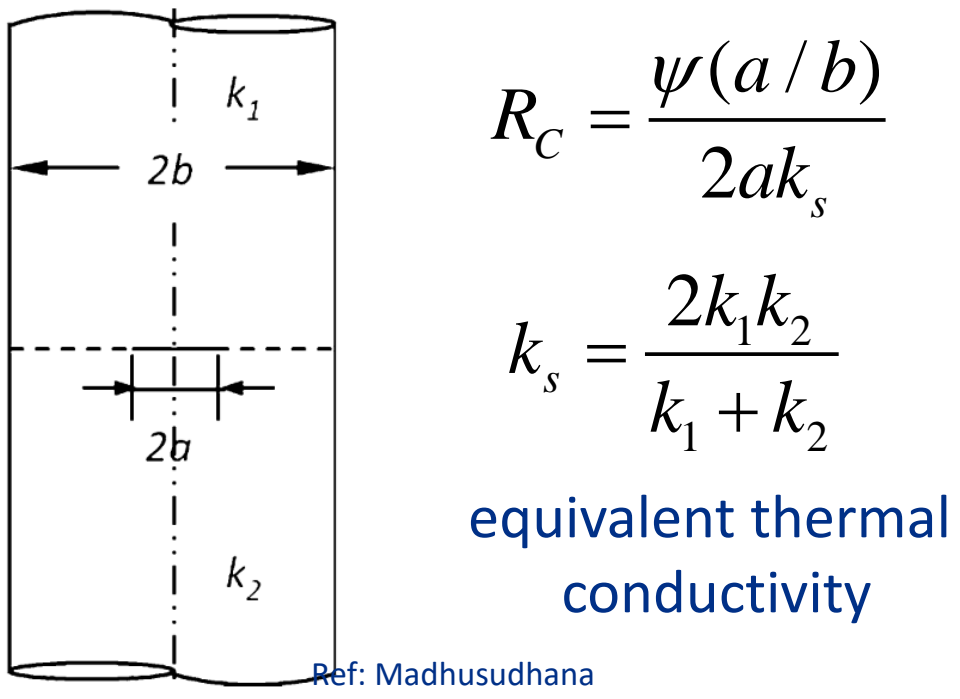

- Contact with multiple spots

Parallel sum: $\quad R_{C}^{-1}=\sum_{i} R_{C i}^{-1}$

For $n$ contacts of average size $a_{m}$ and neglecting variation in $\psi$ :

$$
R_{C}=\frac{\psi(a / b)}{2 n a_{m} k_{s}}
$$




\section{Surface topography (geometry) analysis}

- The contacting surfaces are characterized in terms of their

- Roughness (height distribution of peaks and valleys)

- Asperity slope ('steepness' of peaks and valleys)

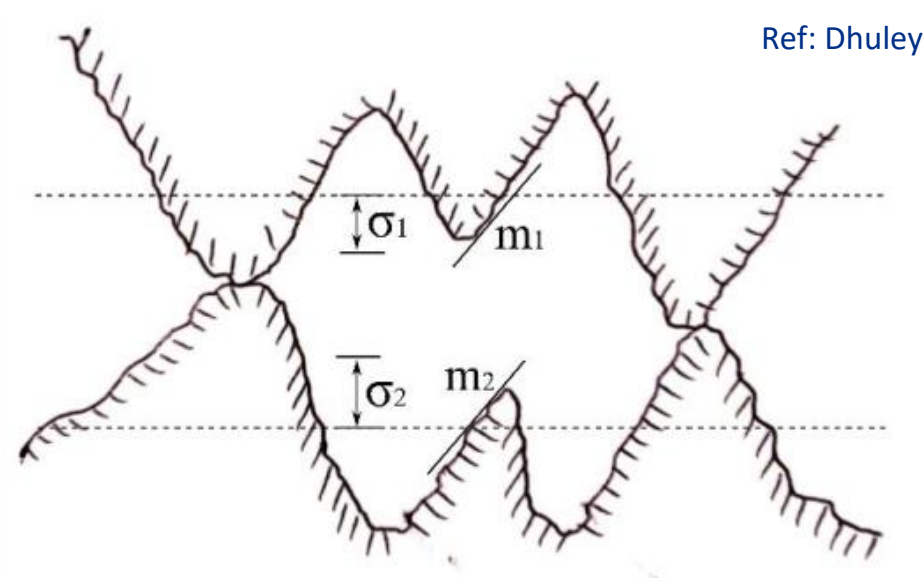

- These are essentially random, but are often assumed to have Gaussian distribution

- $\sigma=$ standard deviation of heights

- $\mathrm{m}=$ standard deviation of slopes

- Relation to typically measured surface roughness

$$
\sigma=R_{q} \approx \sqrt{\frac{\pi}{2}} R_{a} \quad \text { where }
$$

$R_{q}$ is rms surface roughness

$R_{a}$ is average surface roughness 


\section{Surface topography (geometry) analysis}

- Determination of surface geometry parameters

- Roughness parameter ( $z(x)$ is local height/depth)

$$
R_{a}=\frac{1}{L_{\text {sample }}} \int_{0}^{L_{\text {sanple }}}|z(x)| d x \quad \begin{aligned}
& \text { measured using a profilometer } \\
& \text { (eq. laser scanning microscope) }
\end{aligned}
$$

- Average asperity slope

$$
m=\frac{1}{L_{\text {sample }}} \int_{0}^{L_{\text {sample }}}\left|\frac{d z(x)}{d x}\right| d x \quad \begin{aligned}
& \text { computed from profilometer } \\
& \text { measurements }
\end{aligned}
$$

- Empirical correlations (find $\mathrm{m}$ from known $\sigma$ )

Table 1 Correlations for $m$, Gaussian surfaces

\begin{tabular}{lc}
\hline \hline \multicolumn{1}{c}{ Reference } & Correlation \\
\hline Tanner and Fahoum [12] & $m=0.152 \quad \sigma^{0.4}$ \\
Antonetti et al. [13] & $m=0.124 \sigma^{0.743}, \sigma \leqslant 1.6 \mu \mathrm{m}$ \\
Lambert and Fletcher [14] & $m=0.076 \sigma^{0.52}$ \\
\hline \hline
\end{tabular}

Ref: Bahrami et al.

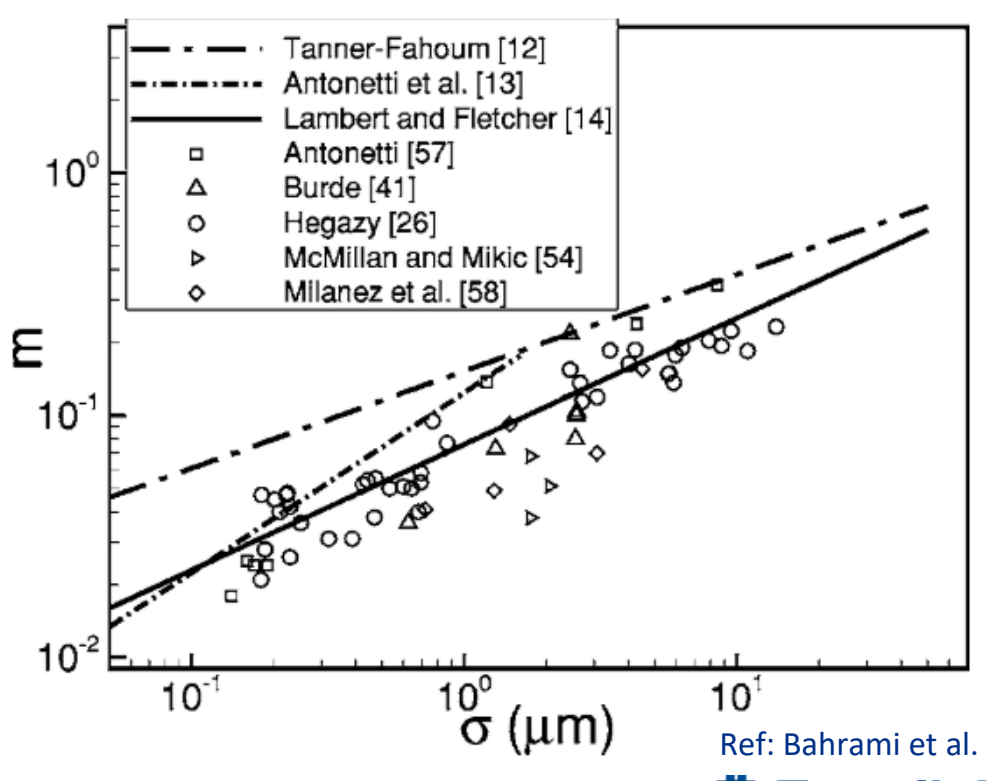




\section{Surface topography (geometry) analysis}

- Equivalent roughness and surface slope are calculated as:

$$
\begin{aligned}
& \sigma_{s}=\sqrt{\sigma_{1}^{2}+\sigma_{2}^{2}} \\
& m_{s}=\sqrt{m_{1}^{2}+m_{2}^{2}}
\end{aligned}
$$

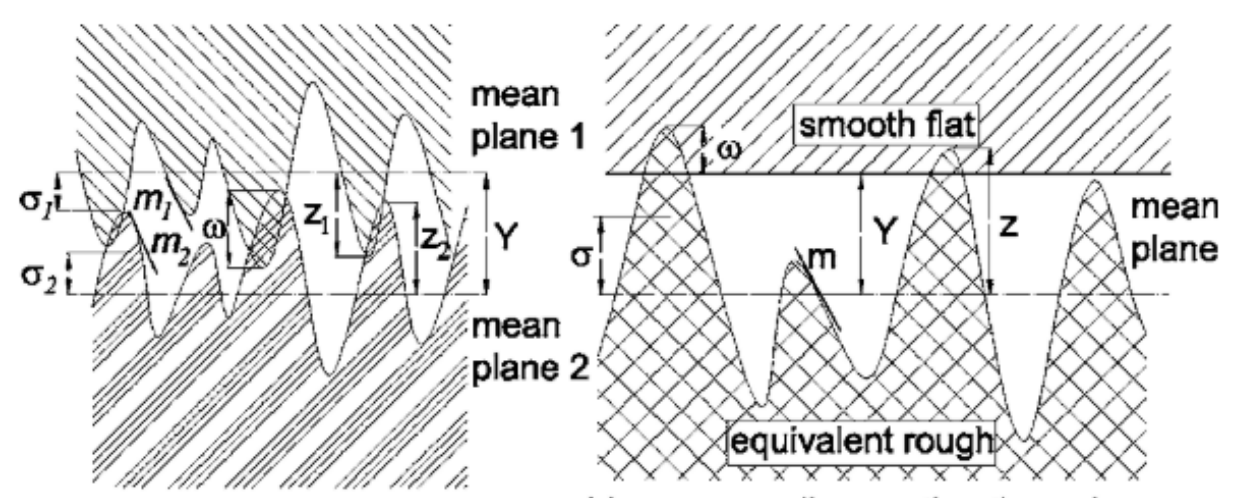

a) section through two contacting surfaces

b) corresponding section through equivalent rough - smooth flat Ref: Bahrami et al.

- Average spot size $\left(a_{m}\right)$ and number of spots per unit area (n) can be now be obtained as:

$n\left(\pi a_{m}^{2}\right)=\frac{A_{\text {real }}}{A_{\text {apparent }}} \quad a_{m}=4\left(\frac{\sigma_{s}}{m_{s}}\right)\left(\frac{A_{\text {real }}}{A_{\text {apparant }}}\right) \exp \left[\left\{\text { erfc }^{-1}\left(\frac{2 A_{\text {real }}}{A_{\text {apparent }}}\right)\right\}^{2}\right] \begin{aligned} & \text { for circular } \\ & \text { contacts }\end{aligned}$

Note: $A_{\text {real }} / A_{\text {apparent }}$ is still unknown and is obtained via deformation analysis 


\section{Asperity deformation analysis}

- Asperities deform 'heavily' because the tiny contact area they represent supports all the applied load

- Deformation, whether elastic or plastic, can be determined by evaluating a plasticity index (several have been proposed)

- Greenwood index: $\psi_{G}=\left(\frac{E^{\prime}}{H_{\text {micro }}}\right) m_{s}$

where $E^{\prime}=2\left(\frac{1-v_{1}^{2}}{E_{1}}-\frac{1-v_{2}^{2}}{E_{2}}\right)^{-1}$ is effective elastic modulus in terms of the

individual elastic modulus and Poisson's ratio; and $\mathrm{H}$ is microhardness of the softer material.

- Plastic contacts: $\psi_{G}>1$ - freshly prepared rough surfaces

- Elastic contacts: $\psi_{G}<0.7$ - polished surfaces; subsequent contact of plastically deformed surfaces 


\section{Asperity deformation analysis}

- For a plastically deformed contact, the ratio of real contact area to apparent contact area is given by:

$\frac{A_{\text {real }}}{A_{\text {apparent }}}=\frac{P_{\text {applied }}}{H_{\text {micro }}} \quad \begin{aligned} & \text { holds for } 10^{-4}<\frac{P_{\text {applied }}}{H_{\text {micro }}}<10^{-2} \text { and a constant value } \\ & H_{\text {micro }}\end{aligned}$ $\frac{A_{\text {real }}}{A_{\text {apparent }}}=\frac{P_{\text {applied }}}{H_{\text {micro }}+P_{\text {applied }}} \quad$ for larger loads

- $H_{\text {micro }}$ is Vickers microhardness; can be approximated as $3^{*}$ yield strength if microhardness is not readily available.

- Microhardness is indentation depth dependent and therefore a function of the surface roughness (asperity heights)

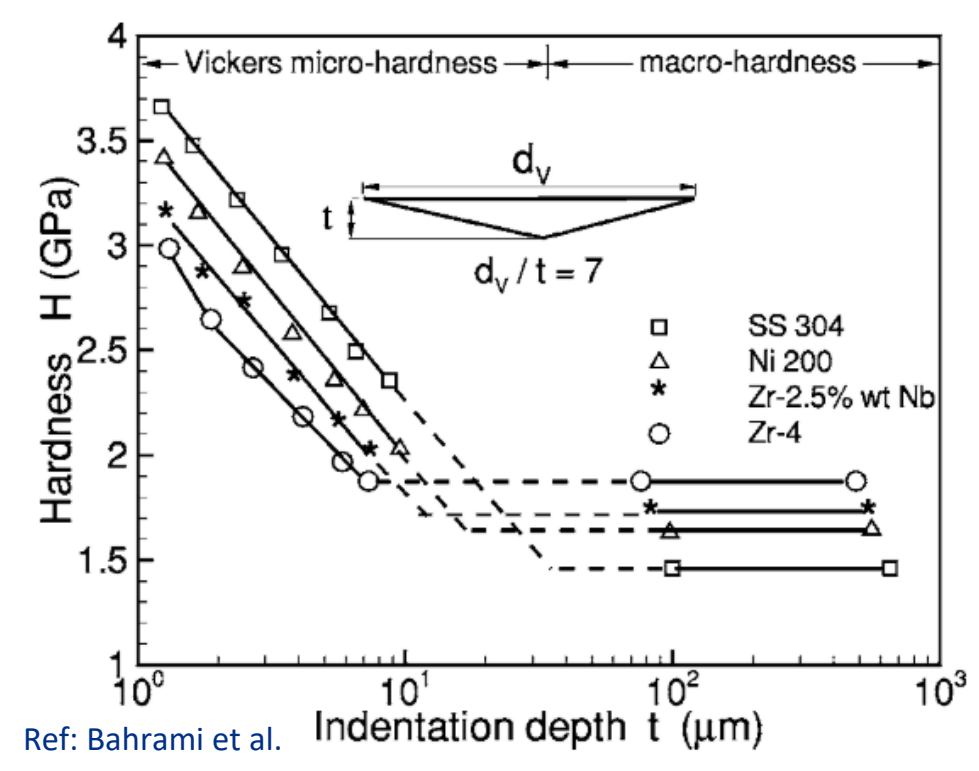




\section{Asperity deformation analysis}

- For an elastically deformed contact, the ratio of real contact area to apparent contact area is given by:

$$
\frac{A_{\text {real }}}{A_{\text {apparent }}}=\frac{1.41 P_{\text {applied }}}{E^{\prime} m_{s}} \quad \begin{aligned}
& \text { asperities are spherically shaped and have } \\
& \text { Gaussian distribution of heights }
\end{aligned}
$$

- Note: For both plastic and elastic contacts,

$A_{\text {real }} \propto P_{\text {applied }} * A_{\text {apparent }}=F_{\text {applied }}$

that is, the applied force determines the real contact area. Since contact resistance $\sim$ real area, it is the applied force that dictates the determines. If the force is unchanged, contact resistance would not change with size of the contact. 


\section{Asperity deformation analysis}

- Now that we have the ratio $A_{\text {real }} / A_{\text {apparent, }}$ average spot size and spots per unit area can be approximated.

- The constriction factor $\Psi(\mathrm{a} / \mathrm{b})$ from the thermal model can also be expressed in terms of the area ratio.

- Researchers have derived several expressions for these. Given below are expressions derived by Antonetti and Yovanovich:

$a_{m}=0.77\left(\frac{\sigma_{s}}{m_{s}}\right)\left(\frac{p_{\text {applied }}}{H_{\text {micro }}}\right)^{0.097} \quad n\left(\pi a_{m}^{2}\right)=\frac{A_{\text {real }}}{A_{\text {apparent }}} \quad \psi=0.76\left(\frac{p_{\text {applied }}}{H_{\text {micro }}}\right)^{-0.027}$

- The knowledge of $n, a_{m}$, and $\Psi$ yields the macroscopic spot resistance.

- There are several models for the macroscopic contact resistance depending upon the model used for $a_{m}, n$, and $F$. 


\section{Macroscopic contact thermal resistance}

- For flat, conforming contacts with plastic deformation, the expression for contact resistance has the form:

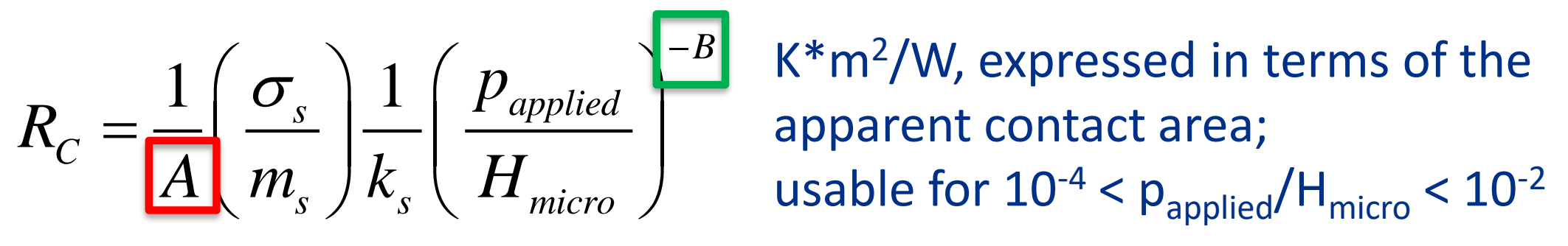

\begin{tabular}{|l||l||l|}
\hline Model & $\mathbf{A}$ & $\mathbf{B}$ \\
\hline Cooper, Mikic, Yovanovich & 1.45 & 0.985 \\
\hline Yovanovich & 1.25 & 0.95 \\
\hline Tien & 0.55 & 0.85 \\
\hline Wheeler & 1.13 & 0.94 \\
\hline Mikic and Rohsenow & 0.9 & 0.941 \\
\hline
\end{tabular}

- See review paper by Lambert and Fletcher for more models, range of validity, etc. (https://arc.aiaa.org/doi/10.2514/2.6221) 


\section{Macroscopic contact thermal resistance}

- For flat, conforming contacts with elastic deformation, the expression for contact resistance has the form:

$$
R_{C}=\frac{1}{\bar{A}}\left(\frac{\sigma_{s}}{m_{s}}\right) \frac{1}{k_{s}}\left(\frac{\sqrt{2} p_{\text {applied }}}{E^{\prime} m_{s}}\right)^{--B}
$$

$\mathrm{K}^{*} \mathrm{~m}^{2} / \mathrm{W}$, expressed in terms of the apparent contact area

\begin{tabular}{|l|l|l|}
\hline Model & A & B \\
\hline Mikic & 1.55 & 0.94 \\
\hline Greenwood and Williamson & $1.75-1.87$ & 0.95 \\
\hline Onions and Archard & $2.38-2.8$ & 0.97 \\
\hline Bush, Gibson, and Thomas & 0.799 & 0.98 \\
\hline
\end{tabular}

- See review paper by Lambert and Fletcher for more models, range of validity, etc. (https://arc.aiaa.org/doi/10.2514/2.6221) 


\section{Thermal analysis: microscopic}

- Microscopic spot resistivity $(l>>a)$ : "bulk" thermal conductivity does not hold validity at the spot (Knudsen regime).

- Heat carriers (free electrons, phonons) on incidence with the physical boundary can reflect back or transmit on to the other side.
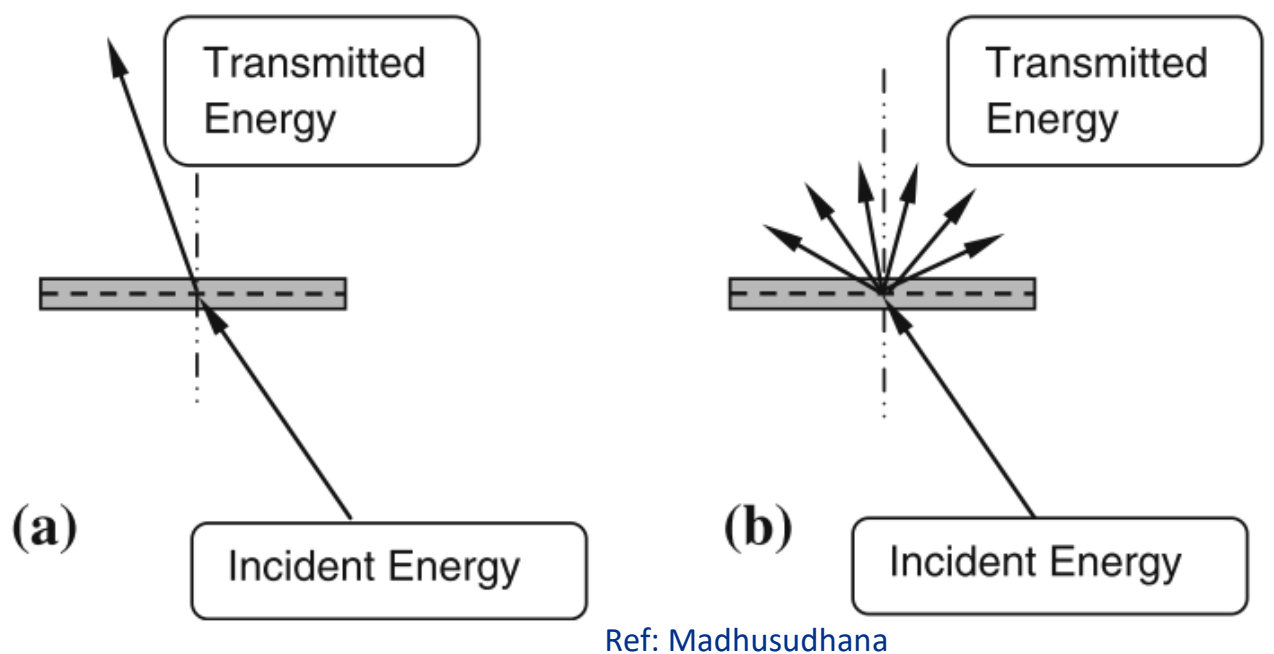

- Analytical solution is obtained by solving the fundamental energy transport equation (Landauer formalism) by assuming a proper transmission probability of the heat carriers. 


\section{Thermal analysis: microscopic}

- Fundamental heat transport equation (see Swartz and Pohl's review 1988)

- Electronic transport (metal-metal interfaces) from side ' 1 ' to ' 2 '

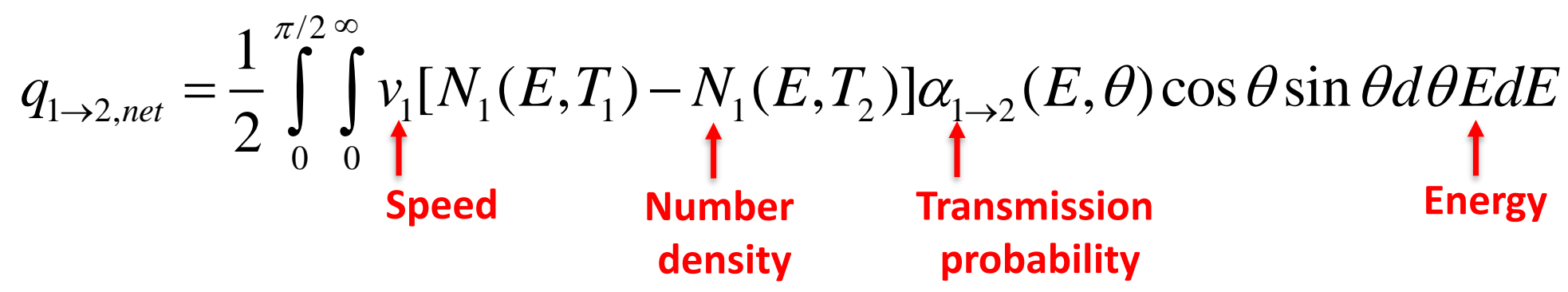

- Phonon transport (metal-dielectric, metal-superconductor interfaces at low temperatures) from side ' 1 ' to ' 2 '

$$
\begin{gathered}
q_{1 \rightarrow 2, \text { net }} \\
=\frac{1}{2} \sum_{j} \int_{0}^{\pi / 2} \int_{0}^{\omega_{\max }} c_{1, j}\left[N_{1}\left(\omega, T_{1}\right)-N_{1}\left(\omega, T_{2}\right)\right] \alpha_{1 \rightarrow 2}(\omega, \theta, j) \cos \theta \sin \theta d \theta \frac{\hbar \omega}{\uparrow} d \omega \\
\text { Sum over three } \\
\text { polarizations }
\end{gathered}
$$

- Figuring out the transmission probability is the main challenge! 


\section{Thermal analysis: microscopic}

- Acoustic mismatch model for phonon transmission probability

- Assumes a 'perfect' interface and specular transmission (Little, 1959)

- The transmission is limited by acoustic impedance mismatch of the two sides

- Works generally at extremely low temperatures $(<1 \mathrm{~K})$ where phonon wavelength is much larger than interface disorder

$$
R_{B}(T)=\left[\frac{\pi^{2}}{15} \frac{k_{B}^{2}}{\hbar^{3}} \sum_{j} c_{1, j}^{-2} \Gamma_{1, j}\right]^{-1} T^{-3}
$$

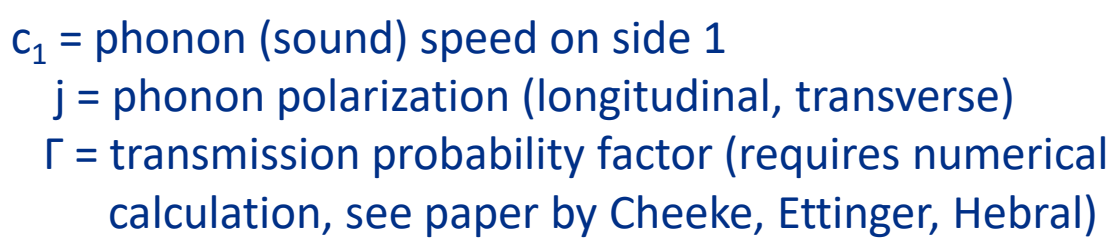

- Diffuse mismatch model for phonon transmission probability

- All phonon incident on the interface scatter diffusively, forward scattering probability equals ratio of density of phonon states (Swartz and Polh, 1989)

- Works at warmer temperatures where phonon wavelength is comparable to interface disorder

$$
R_{B}(T)=\left[\frac{\pi^{2}}{15} \frac{k_{B}^{2}}{\hbar^{3}} \frac{1}{2} \frac{\sum_{j} c_{1, j}^{-2} \sum_{j} c_{2, j}^{-2}}{\sum_{i, j} c_{i, j}^{-2}}\right]^{-1} T^{-3} \quad \begin{aligned}
& \text { Expression valid at temperature } \\
& \text { < Debye temperature }
\end{aligned}
$$




\section{Thermal analysis: microscopic}

- Diffuse mismatch model for electron transmission probability

- All electrons incident on the interface scatter diffusively, forward scattering probability equals ratio of density of electron states (Gundrum et al., 2005)

- Analogy drawn from phonon diffuse mismatch model, not has been verified as extensively!

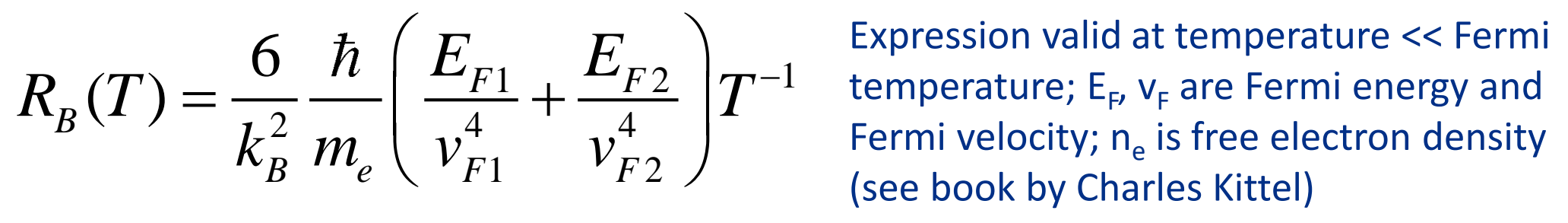

- Notes

- Phonon models predict $\mathrm{T}^{-3}$ dependence, as is seen often times for metal-dielectric and metal-superconductor contacts at low temperatures ( $<<$ Debye temperature).

- Electron model predicts $\mathrm{T}^{-1}$ dependence, as is common with well prepared clean metal-metal contacts (eg. gold plated copper). Gundrum et al. saw $\mathrm{T}^{-1}$ for $\mathrm{Cu}-\mathrm{Al}$ contacts even in $77-300 \mathrm{~K}$.

- These model need $A_{\text {real }} / A_{\text {apparent }}$ ratio for use with pressed contacts 


\section{A simple model for pressed contacts}

- The contacts are assumed to be flat and conforming

- Metal-metal contacts

$$
R_{B}(T)=\frac{1}{A}\left(\frac{\sigma_{s}}{m_{s}}\right) \frac{1}{k_{s}}\left(\frac{p_{\text {applied }}}{H_{\text {micro }}}\right)^{-B}+\frac{6}{k_{B}^{2}} \frac{\hbar}{m_{e}}\left(\frac{E_{F 1}}{v_{F 1}^{4}}+\frac{E_{F 2}}{v_{F 2}^{4}}\right) T^{-1}\left(\frac{p_{\text {applied }}}{H_{\text {micro }}}\right)^{-1}=\left(\mathrm{A}_{\text {real }} / \mathrm{A}_{\text {apparent }}\right)^{-1}
$$

- Metal-dielectric, metal-superconductor contacts

$$
R_{B}(T)=\frac{1}{A}\left(\frac{\sigma_{s}}{m_{s}}\right) \frac{1}{k_{s}}\left(\frac{p_{\text {applied }}}{H_{\text {micro }}}\right)^{-B}+\left[\frac{\pi^{2}}{15} \frac{k_{B}^{2}}{\hbar^{3}} \frac{1}{2} \frac{\sum_{j} c_{1, j}^{-2} \sum_{j} c_{2, j}^{-2}}{\sum_{i, j} c_{i, j}^{-2}}\right]^{-1} T^{-3}\left(\frac{p_{\text {applied }}}{H_{\text {micro }}}\right)^{-1}
$$




\section{Common observations at low temperature (LHe)}

- Dependence on temperature

$R_{C} \sim T^{-1}$ : pure or lightly oxidized metallic contacts (oxide $<<$ deBroglie $\lambda_{\text {electron}}$ )

$R_{C} \sim T^{-2}$ : oxidized metallic contacts (deBroglie $\lambda_{\text {electron }}<<$ oxide $<<\lambda_{\text {phonon }}$ )

$R_{C} \sim T^{-2<n<-1}$ : practical metallic contacts (limited exposure to oxygen)

$R_{C} \sim T^{-3}$ : contact with a superconductor $\left(\mathrm{T}<<\mathrm{T}_{\text {crit }}\right)$

- Weideman Franz law analogy for contacts

$R_{C, \text { thermal }}=\frac{R_{C, \text { elec }}}{L_{0}} T^{-1} \quad \begin{aligned} & \mathrm{L}_{0} \text { is theoretical Lorenz number } \\ & \left(=2.44 \times 10^{-8} \mathrm{~W} \Omega / \mathrm{K}^{2}\right)\end{aligned}$

- $R_{C, \text { thermal }} \sim T^{-1}$ at lower temperature since $R_{C, \text { elec }}$ is constant

- Gives an upper bound of thermal contact resistance as an additional heat transfer channel (phonon) can be present.

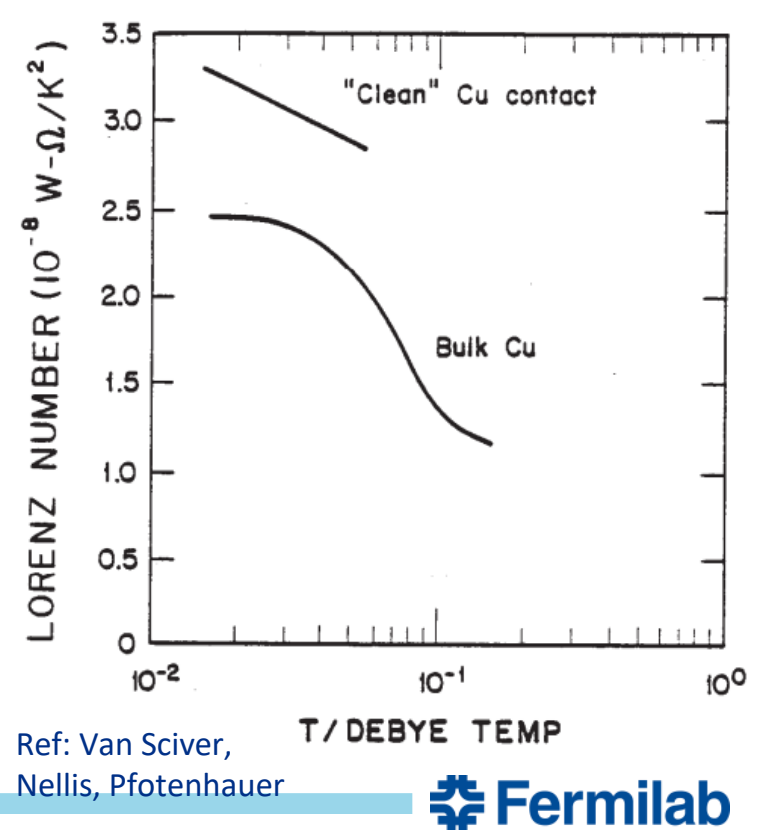




\section{Measurement techniques}

- Steady state heat flow method

- Uses a heater $(H)$ to set up a heat flow across the contact and two thermometers $\left(T_{1}, T_{2}\right)$ to measure temperature jump

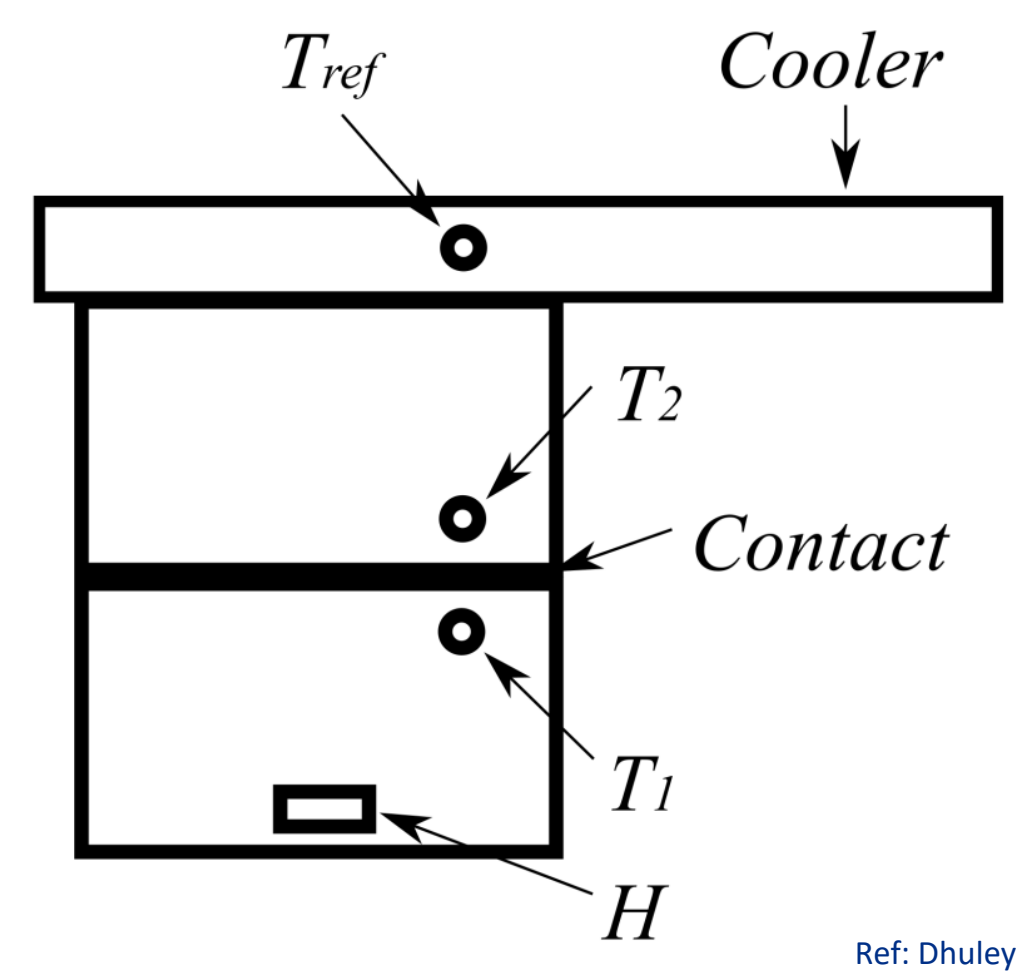

Steady state heat flow method implemented on a cryocooler
Contact resistance is determined as:

$R_{C}\left(T_{\text {avg }}\right)=\frac{T_{1}-T_{2}}{H}$

with $T_{a v g}=0.5\left(T_{1}+T_{2}\right)$

Notes:

- Keep $T_{1}-T_{2}<1-2 \%$ of $T_{\text {avg }}$ to accurately capture the power law

- Locate thermometers as close to the contact as practical

- Systematic uncertainty in $T_{1}-T_{2}$ can be significant, especially for small $T_{1}-T_{2}$ 


\section{Measurement techniques}

- Two-heater method

- Uses a thermometer $(T)$ upstream and two heaters $\left(H_{1}, H_{2}\right)$ across the contact

- Two-step measurement:

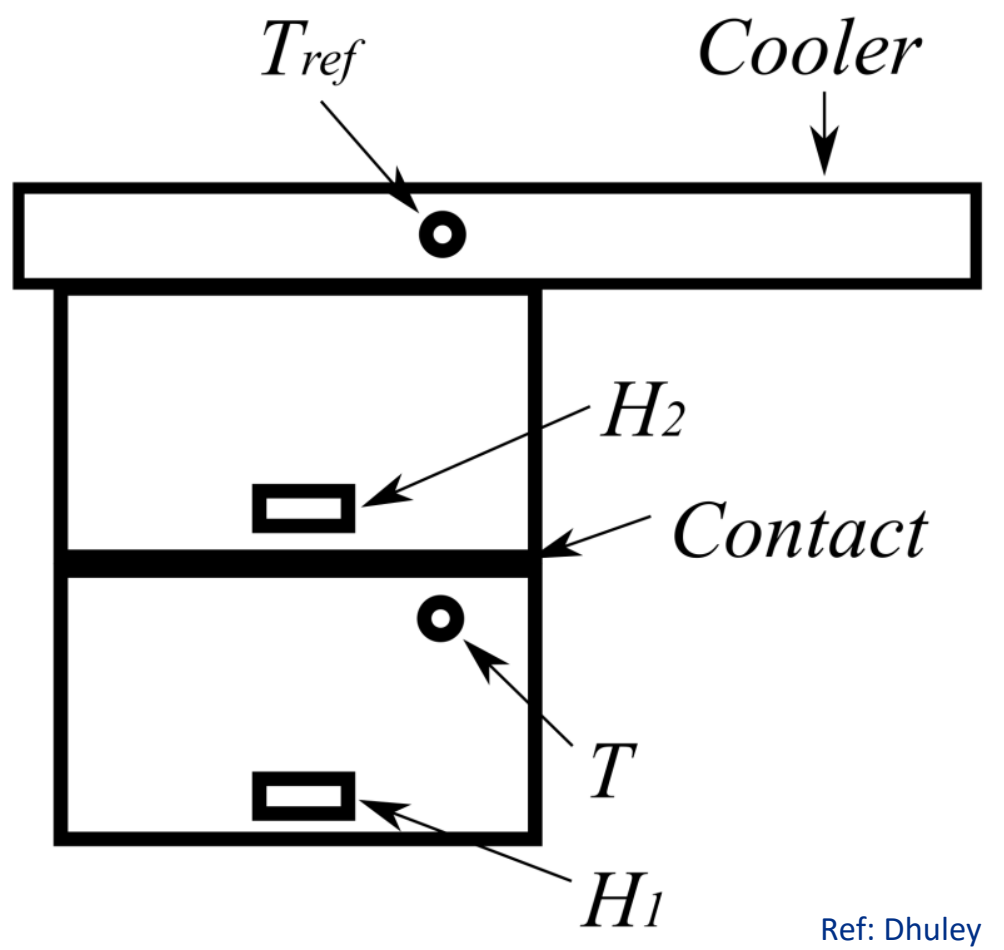

Two-heater method implemented on a cryocooler (a) $H_{1}=H, H_{2}=0$, note $T=T_{a}$

(b) $H_{1}=0, H_{2}=\mathrm{H}$, note $T=T_{b}$

Contact resistance is determined as:

$R_{C}\left(T_{a v g}\right)=\frac{T_{a}-T_{b}}{H}$

with $T_{a v g}=0.5\left(T_{a}+T_{b}\right)$

\section{Notes:}

- To work, the method needs $\mathrm{H}$ to be "equal" in steps $a$ and $b=>$ careful evaluation of heater wire heat leak

- Systematic uncertainty in $T_{1}-T_{2}$ can be very small, especially for small $T_{1}-T_{2}$ 


\section{Measurement techniques}

- Electrical contact resistance

- Useful for metal-metal contacts near and below liquid helium temperature where the Wiedeman Franz law holds

- In practice, measurements are done at $4.2 \mathrm{~K}$ to determine upper bound of thermal contact resistance; extrapolate to lower temperature using WF law

- Measurement is much easier (and faster) that direct thermal resistance

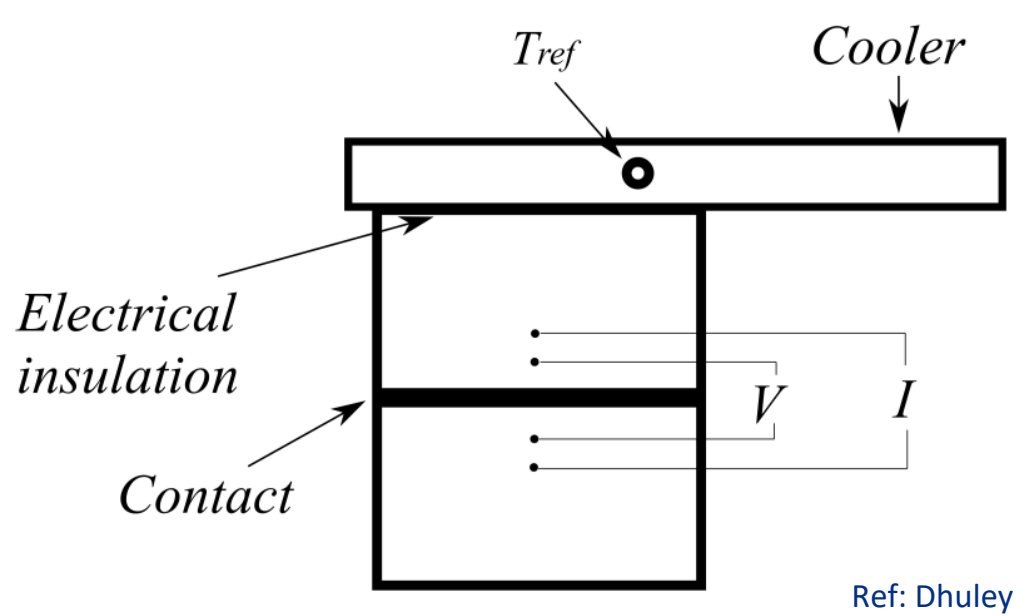

DC 4-wire measurement can yield few tenths of a $\mu \Omega$

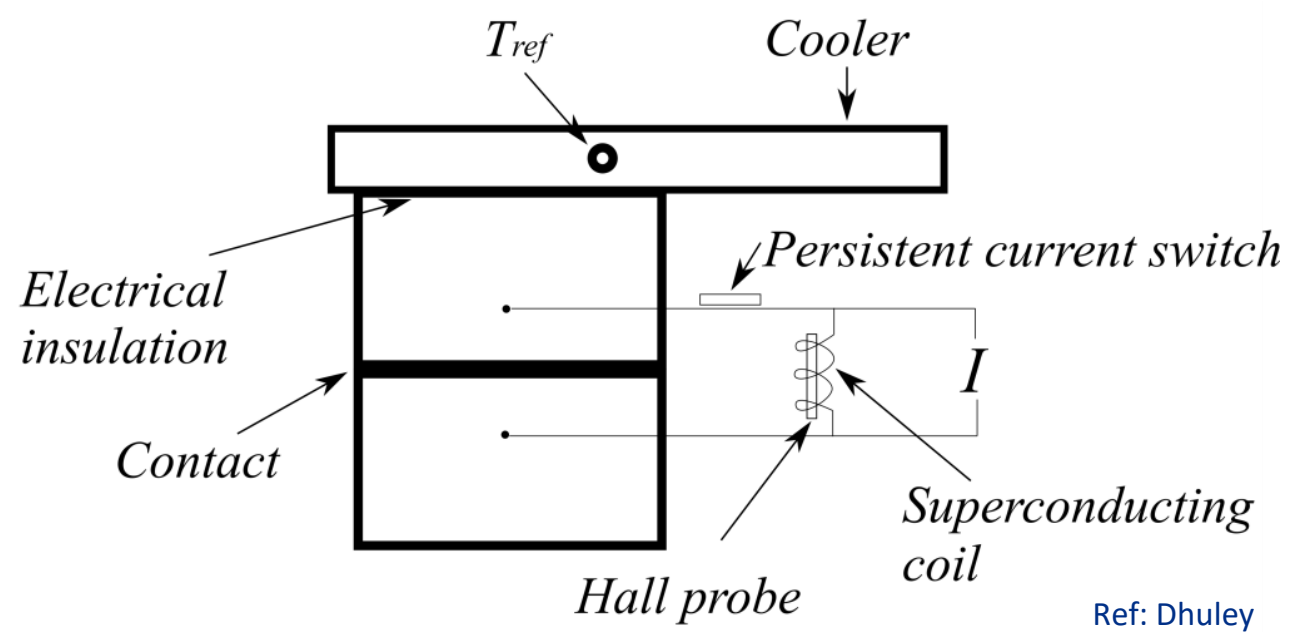

Current decay technique is found to be suitable to measure as low as a few $\mathrm{n} \Omega$ 


\section{Example: SuperCDMS SNOLAB cryostat}

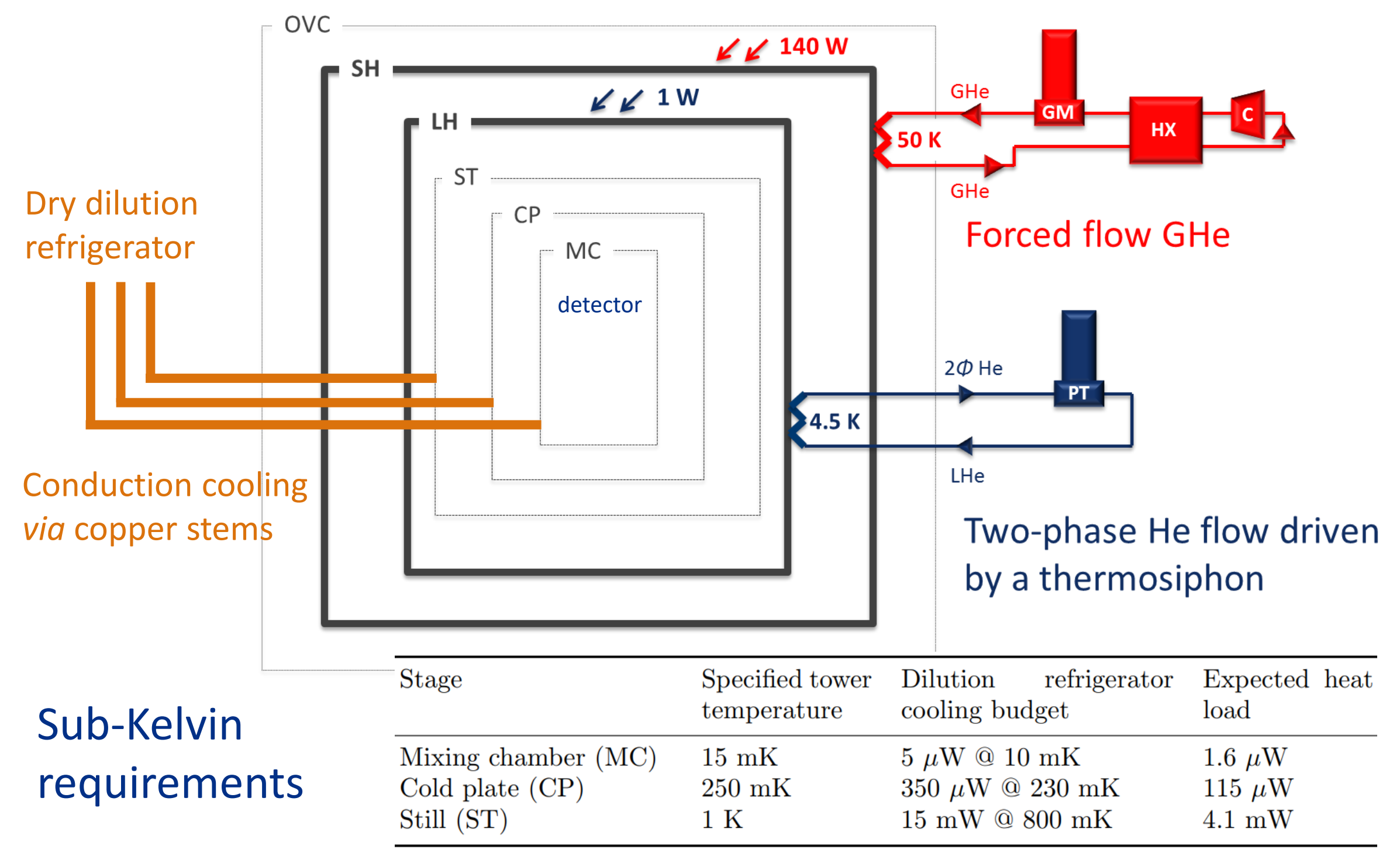




\section{Example: SuperCDMS SNOLAB cryostat}

Sub-Kelvin conduction stems (8 feet long): contacts (flat, cylindrical), flex straps Dilution fridge

interface

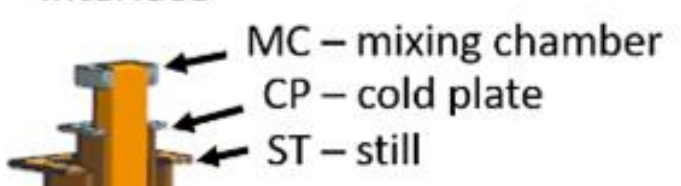

MC- mixing chamber

$\mathrm{CP}$ - cold plate

T- ST - still

Fridge-tails
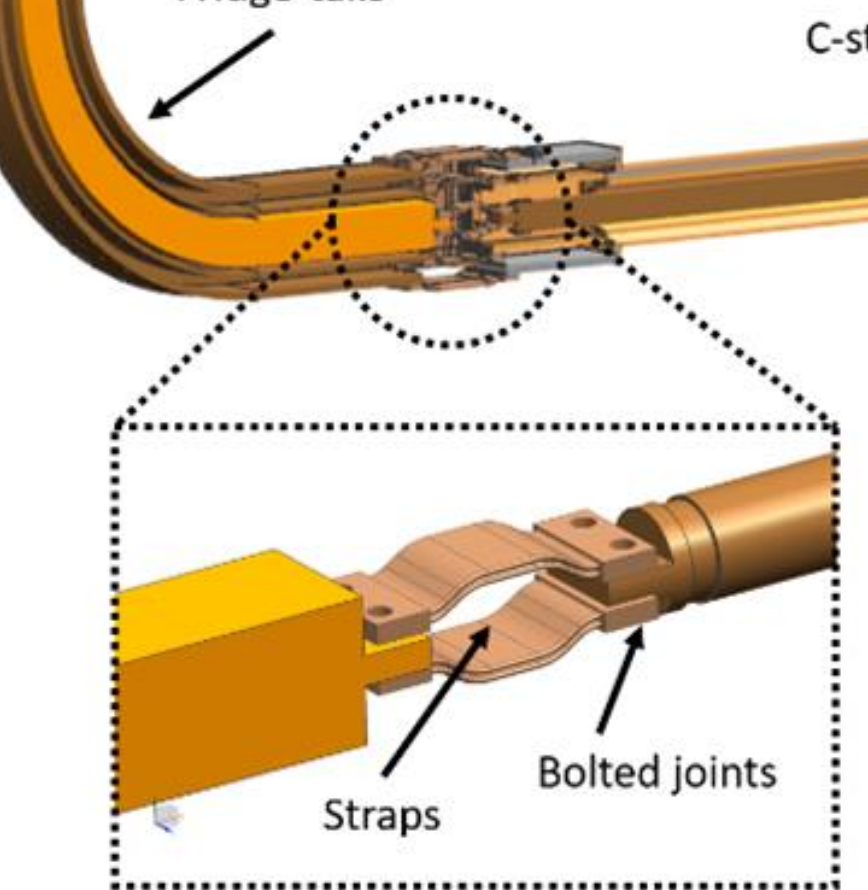

Dhuley et al.: https://doi.org/10.1088/1757-899X/278/1/012157 


\section{Conduction stem: Flat and cylindrical joints}

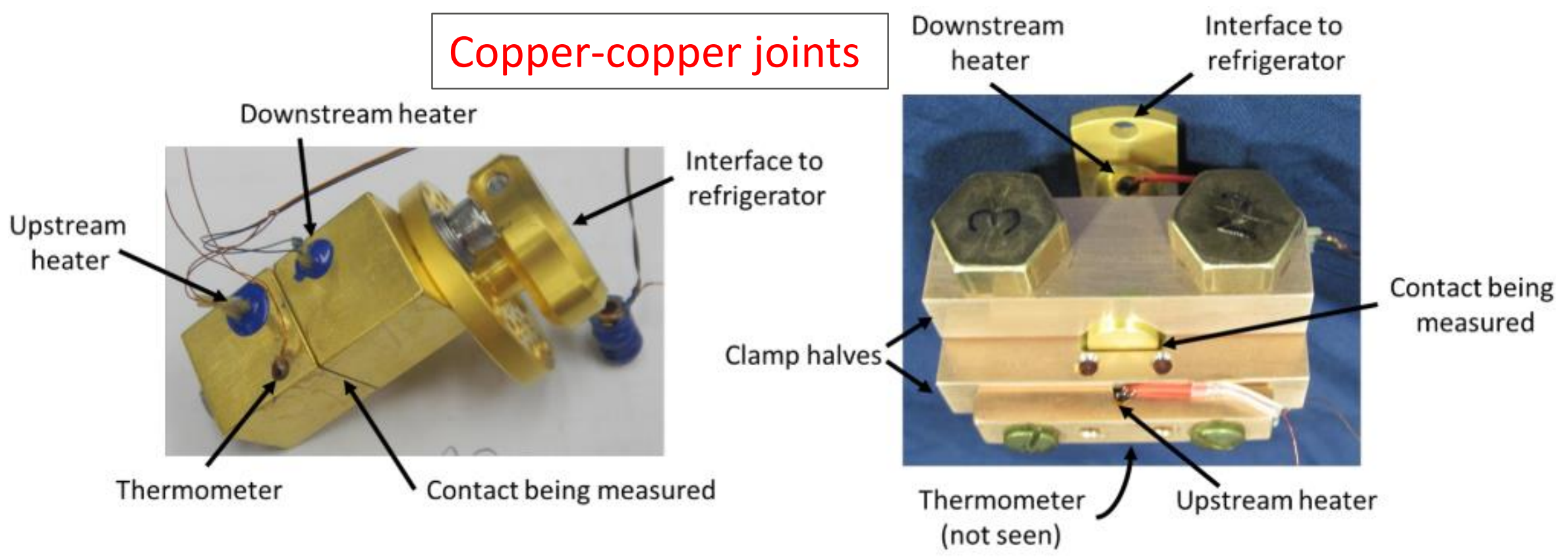

- Surface roughness $=0.2 \mu \mathrm{m}$

- Gold plating $0.5 \mu \mathrm{m}$ over a nickel plate of $1.2 \mu \mathrm{m}$ (better adhesion)

- Pressed using Belleville disc washers or differential thermal contraction between screw (brass) and plates (copper): Force $\sim 3 \mathrm{kN}$

- Measured between $60 \mathrm{mK}$ and $10 \mathrm{~K}$ (dilution fridge, ADR, pulse tube) 


\section{Conduction stem: Flexible linkages}

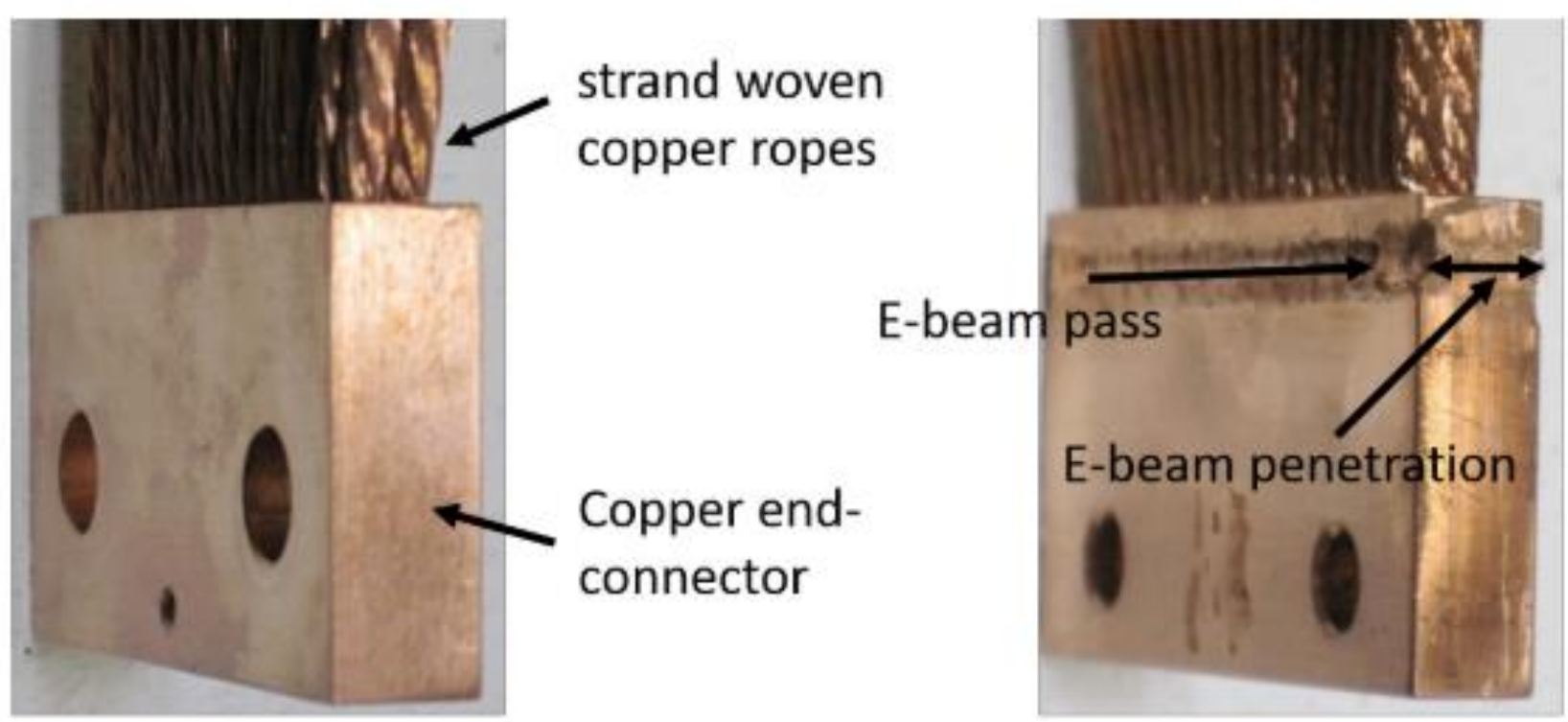

Commercial off-the-shelf thermal strap

- Works well above $1 \mathrm{~K}$ - controlled by conductance of flex ropes

- Not suitable $<1 \mathrm{~K}$ - contact resistance at the end-connectors starts to dominate

- E-beam welding fused the ropes to the end-connector, made the strap suitable for $<1 \mathrm{~K}$ use 


\section{Contact resistance measurements for SuperCDMS}

Sub-Kelvin measurements on an ADR using the two-heater method

Flat joint

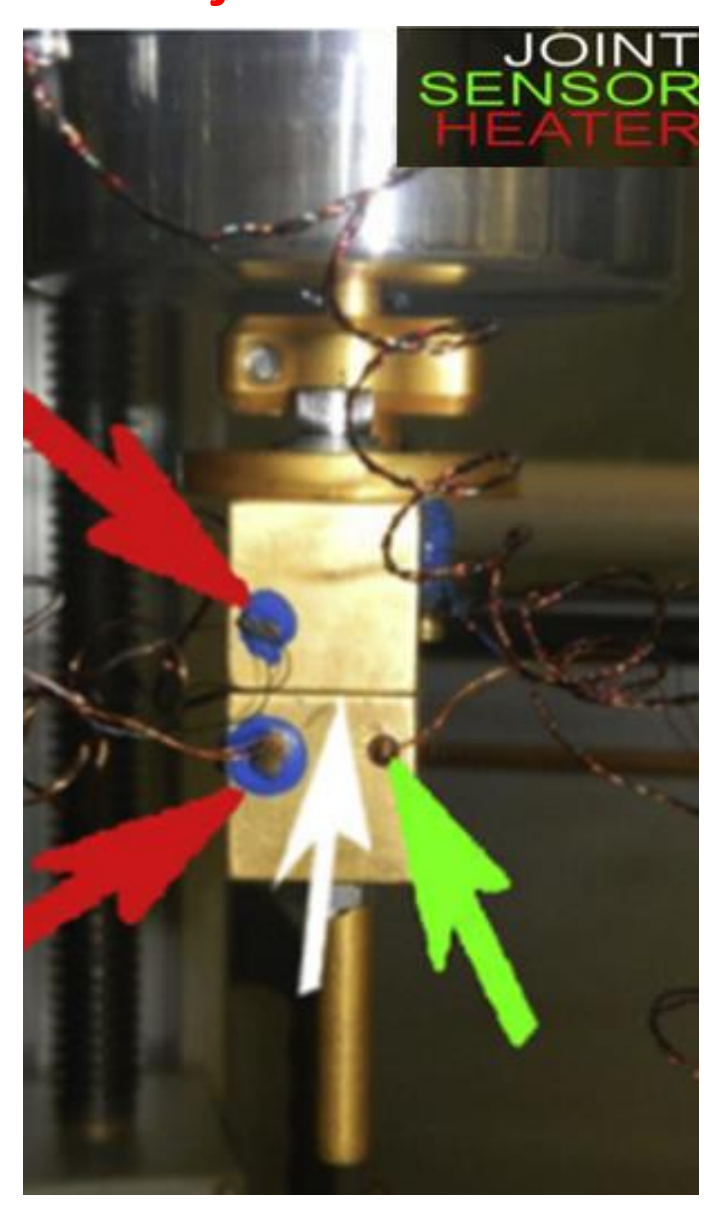

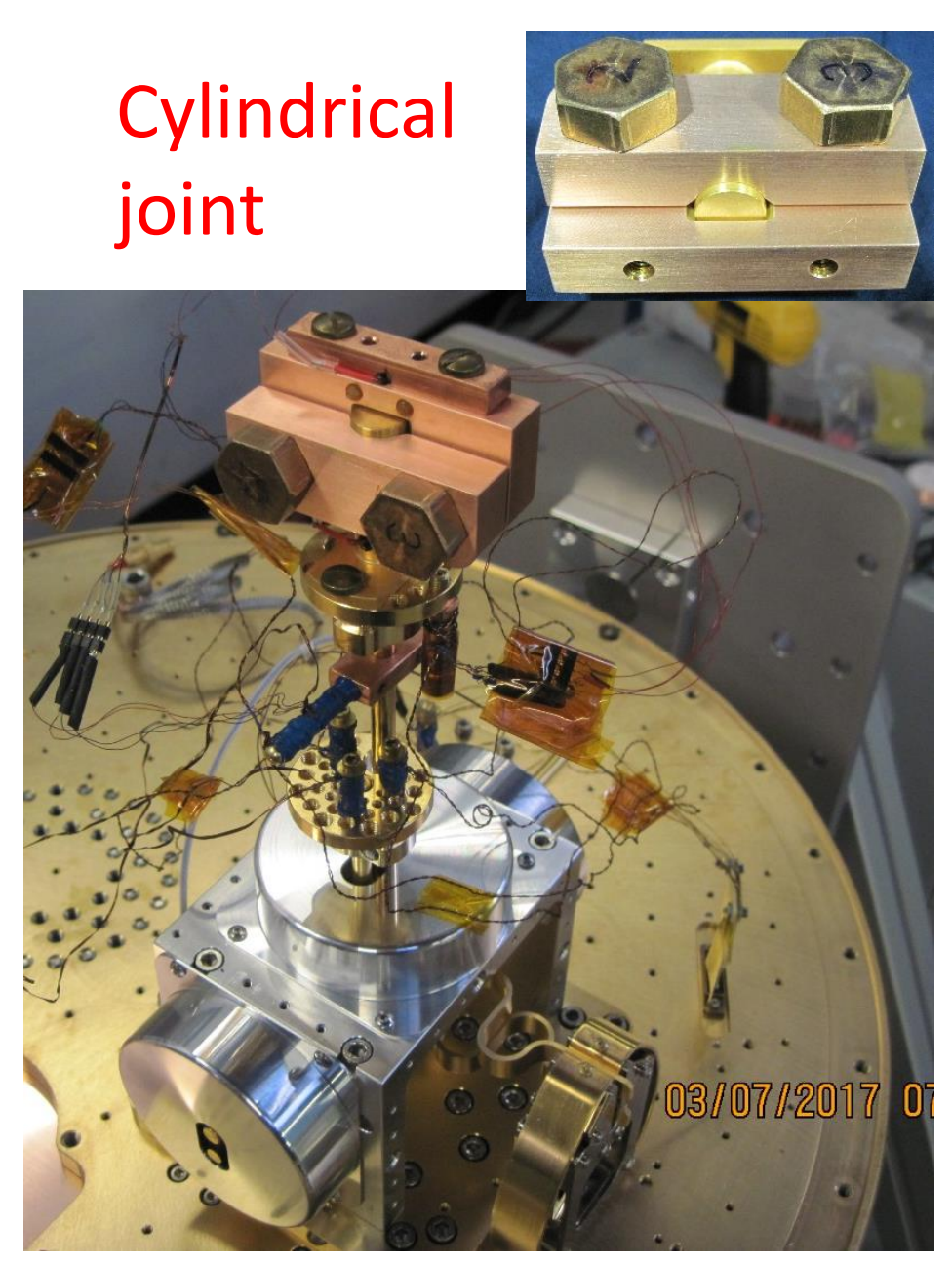




\section{Example: Conduction cooled SRF cavity}

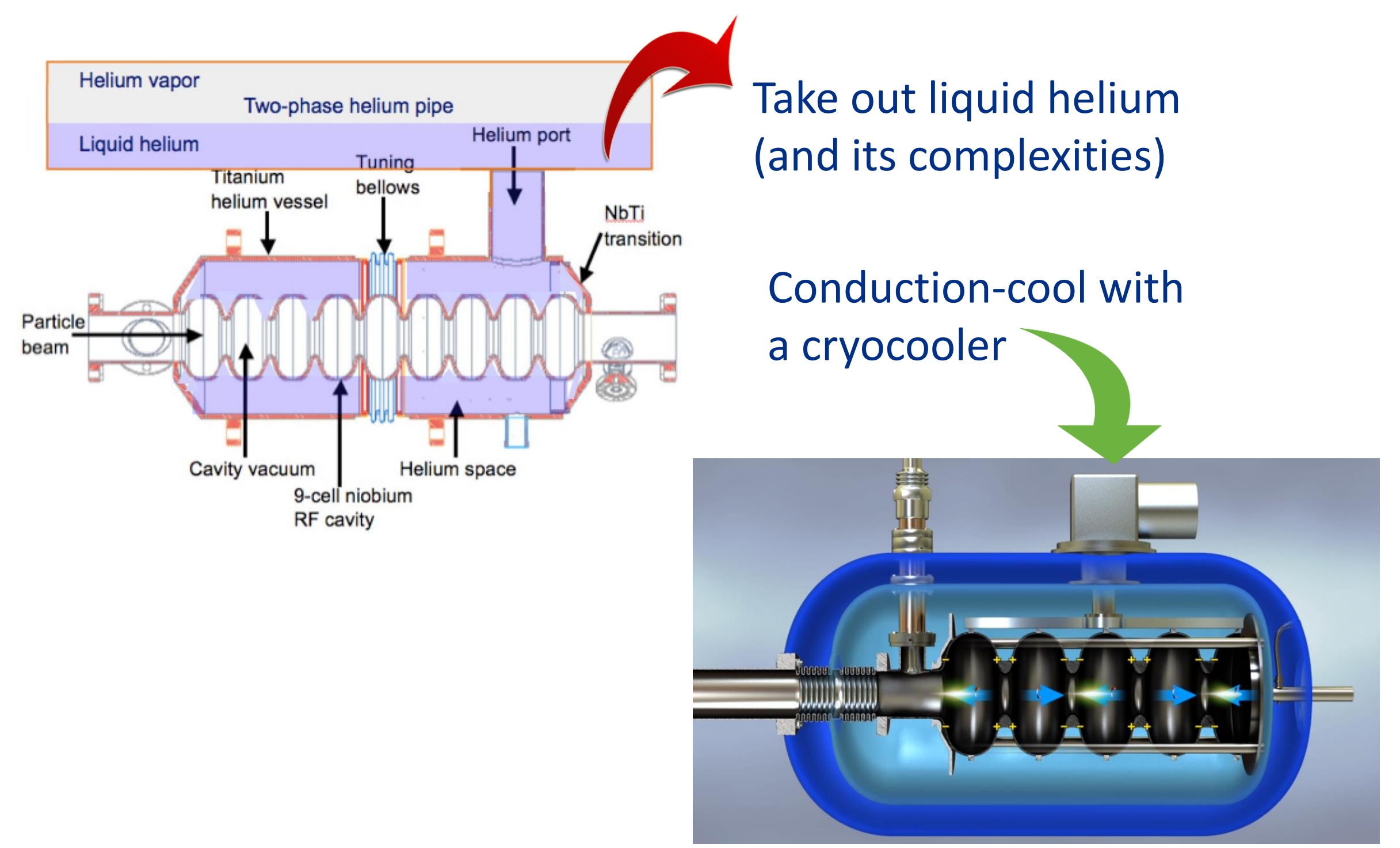




\section{Example: Conduction cooled SRF cavity}

Niobium SRF cavity dissipates heat when exposed to RF fields

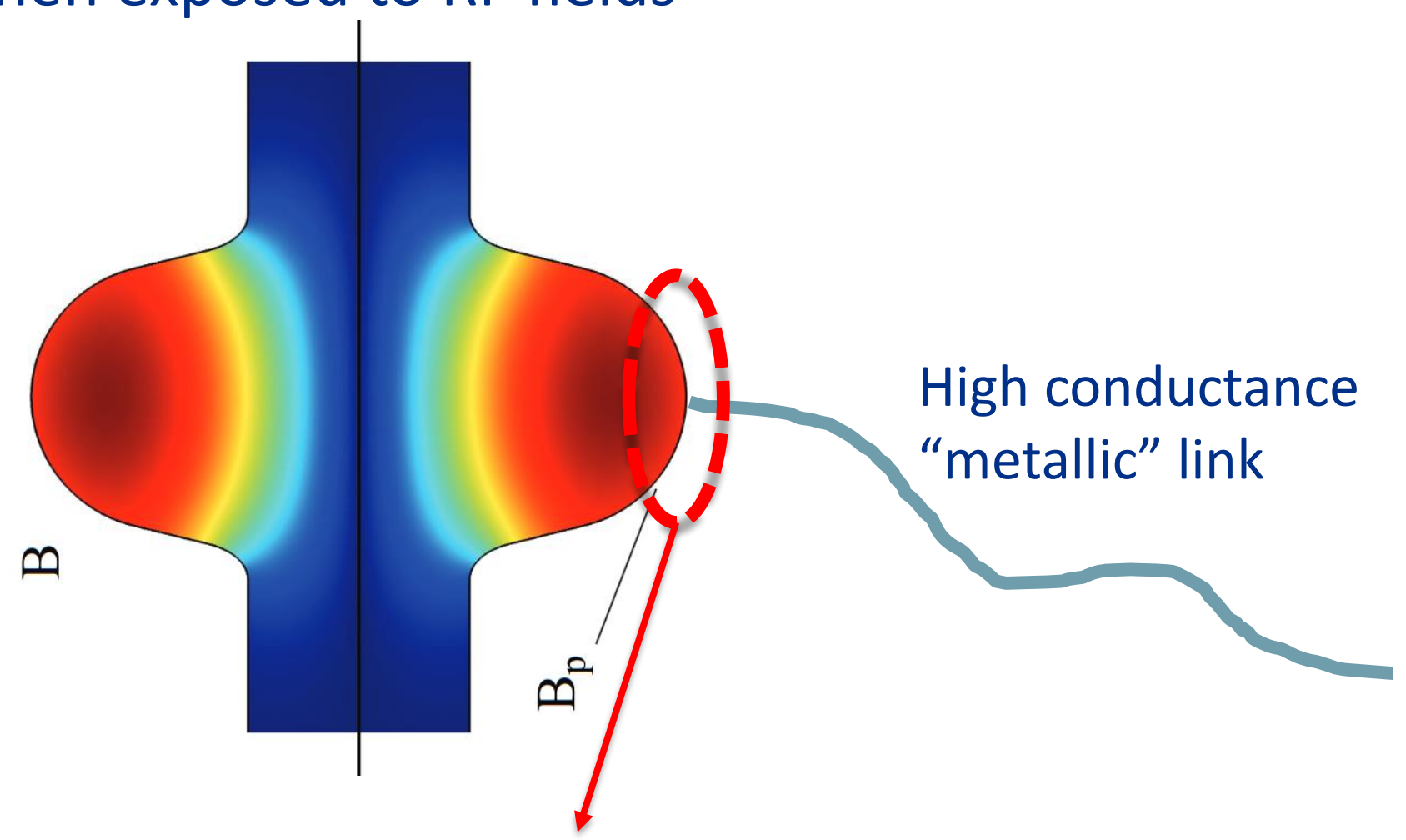

Metal-superconductor pressed thermal contact!

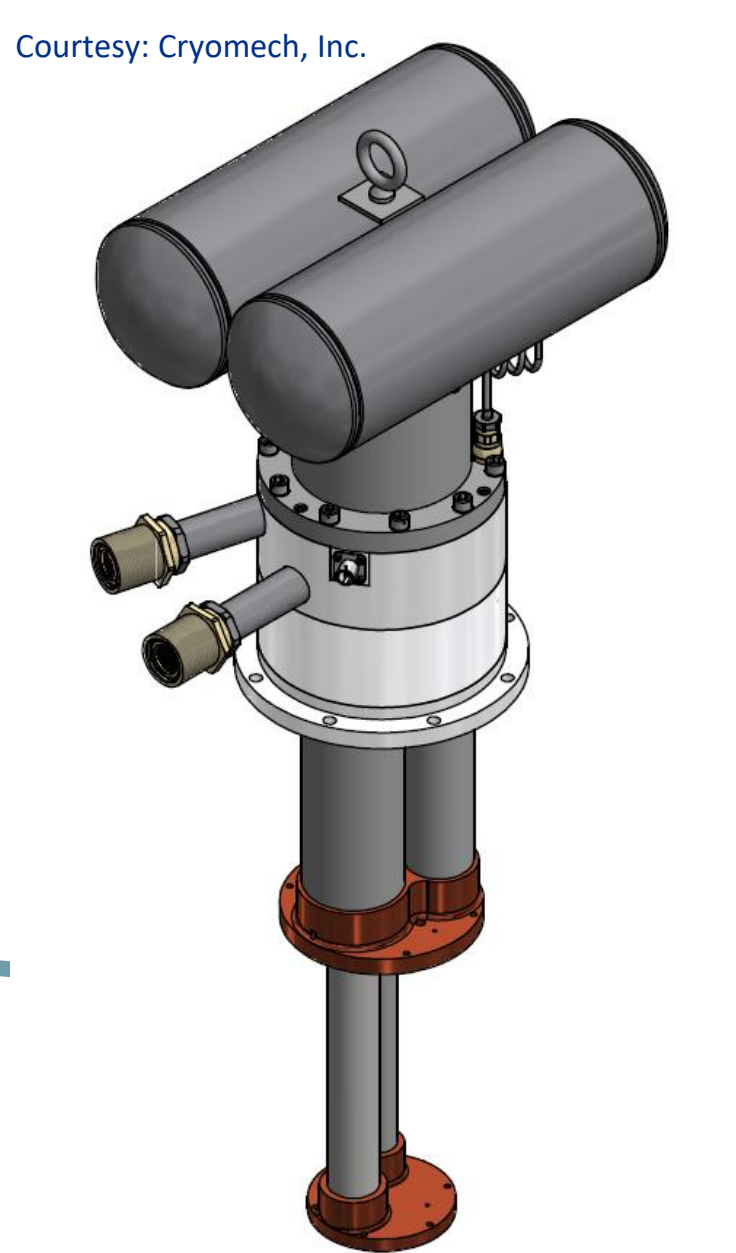

Pulse tube cryocooler absorbs the heat 


\section{Metal-superconductor joints for conduction cooling}

Joint material:

$5 \mathrm{~N}$ aluminum (Al), SRF grade

niobium $(\mathrm{Nb})$

Surface prep:

Roughness $\approx 1 \mu \mathrm{m}$

Cleaning: Al plate in $\mathrm{NaOH}$ solution

$\mathrm{Nb}$ plate via $\mathrm{BCP}$

Force application:

Belleville disc washers of various stiffnesses (also help maintain bolt tension); range $4-14 \mathrm{kN}$

Contact resistance measurements:

$\mathrm{T}=3-5 \mathrm{~K}$, two-heater method, pulse tube cryocooler

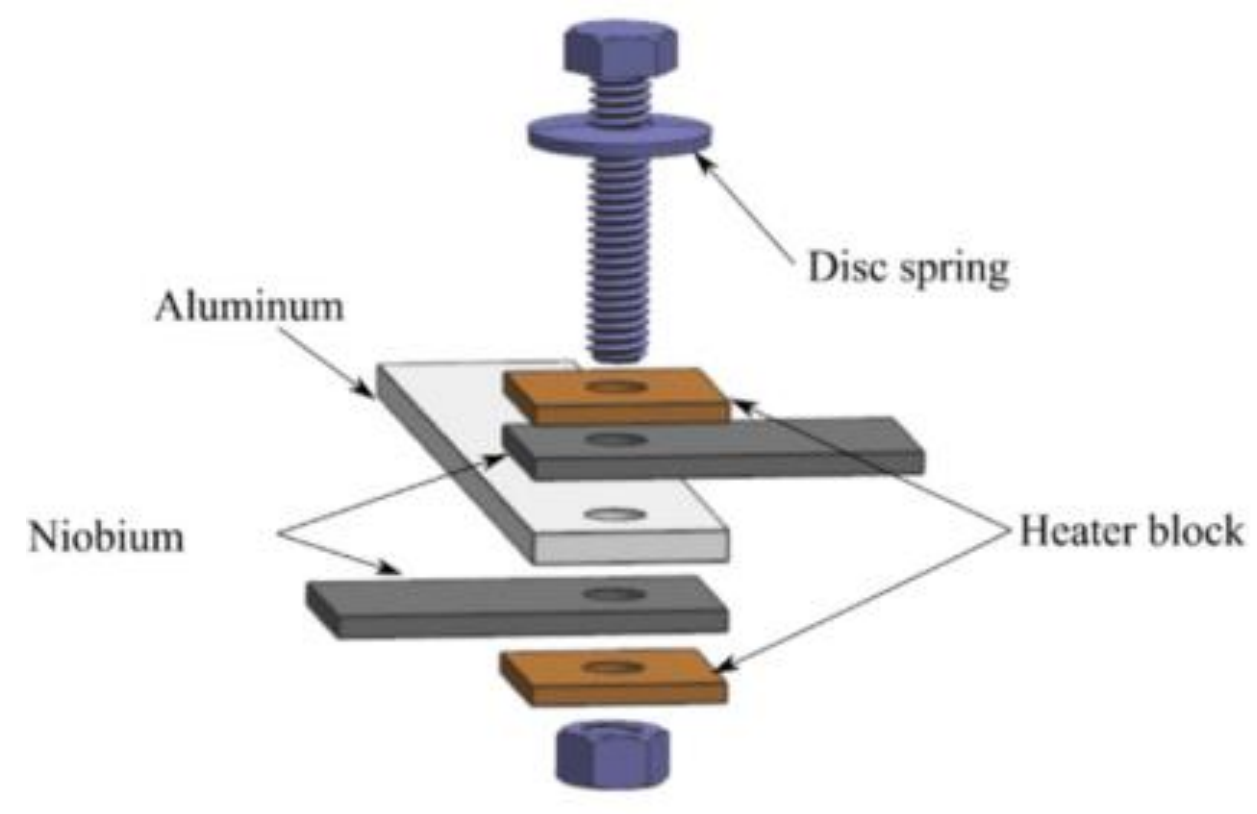

(a)

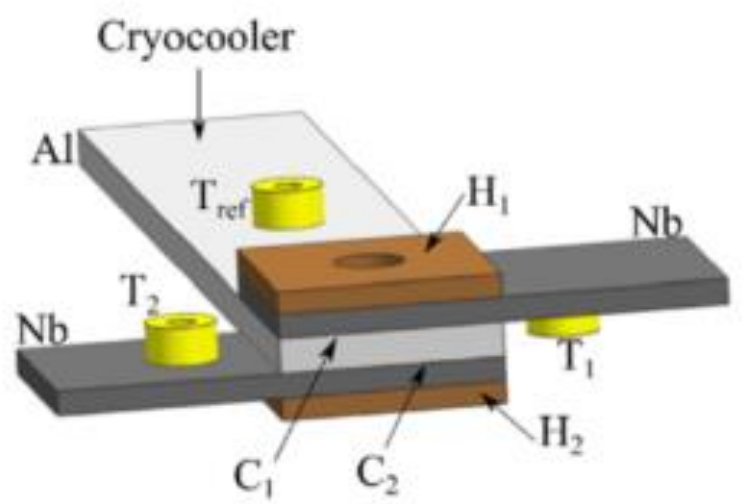

Dhuley et al. : https://doi.org/10.1016/i.cryogenics.2018.06.003

苇 Fermilab 


\section{$\mathrm{Nb}-\mathrm{Al}$ contact resistance: temperature dependence}

Dry joints

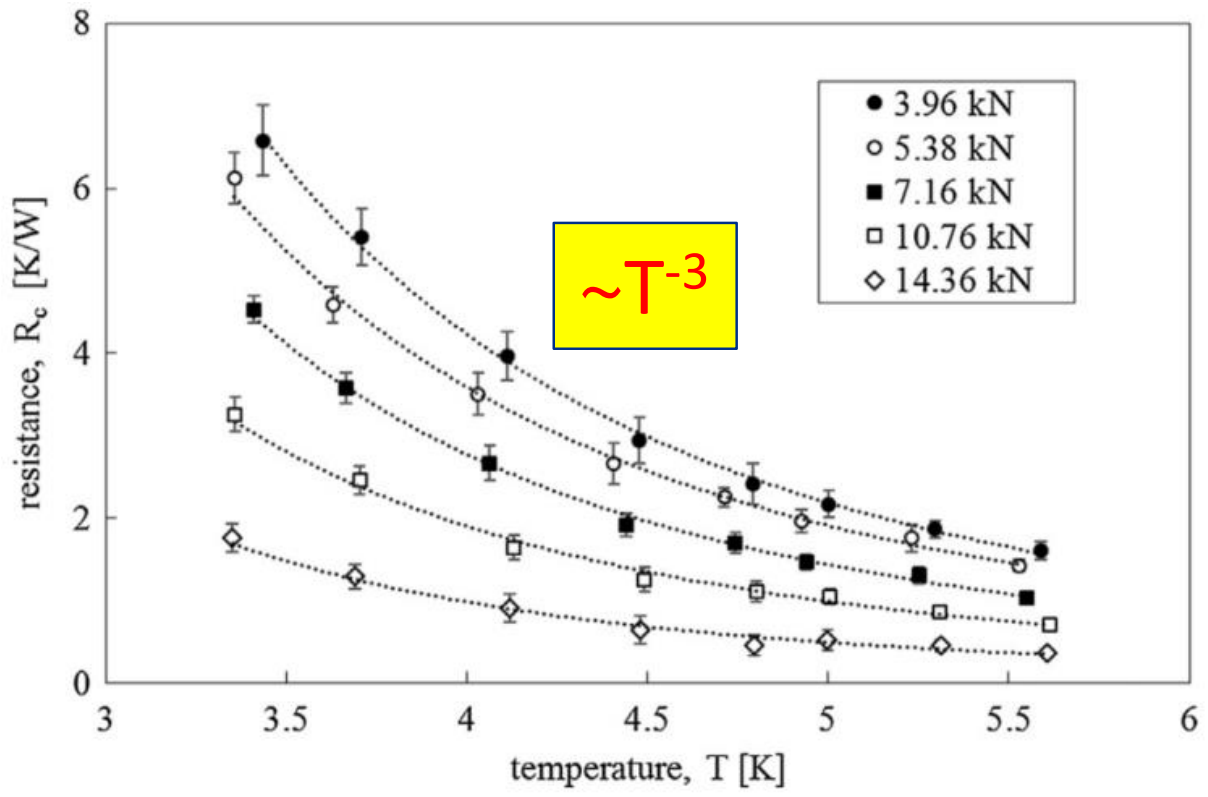

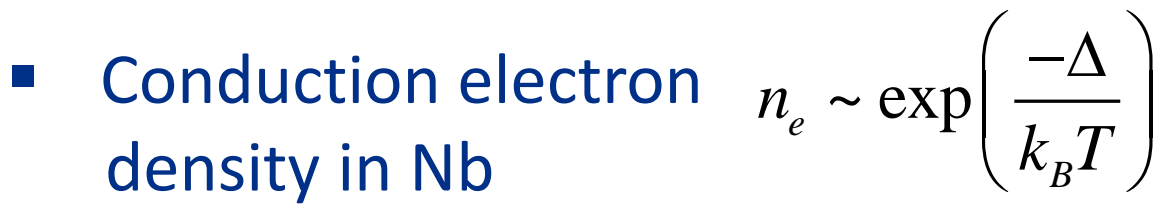

- Phonons increasingly dominate the heat transfer with decreasing temperature: $R_{C} \sim T^{-3}$
Joints with pressed indium foil

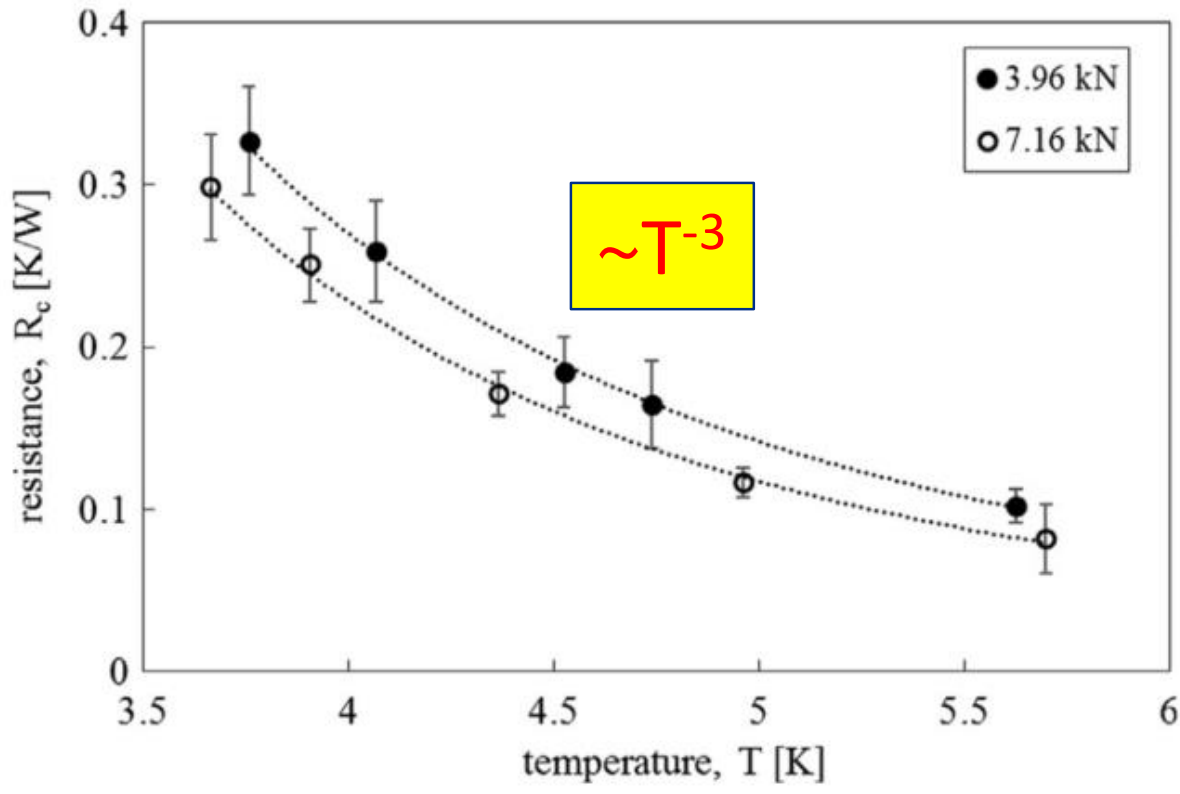

- $10 x$ improvement with pressed thin foil indium (5 mils)

- fills microscopic gaps

- flow pressure $2 \mathrm{MPa}$ at room temperature, about four times higher near $4 \mathrm{~K}$ 


\section{$\mathrm{Nb}$-Al contact resistance: force dependence}
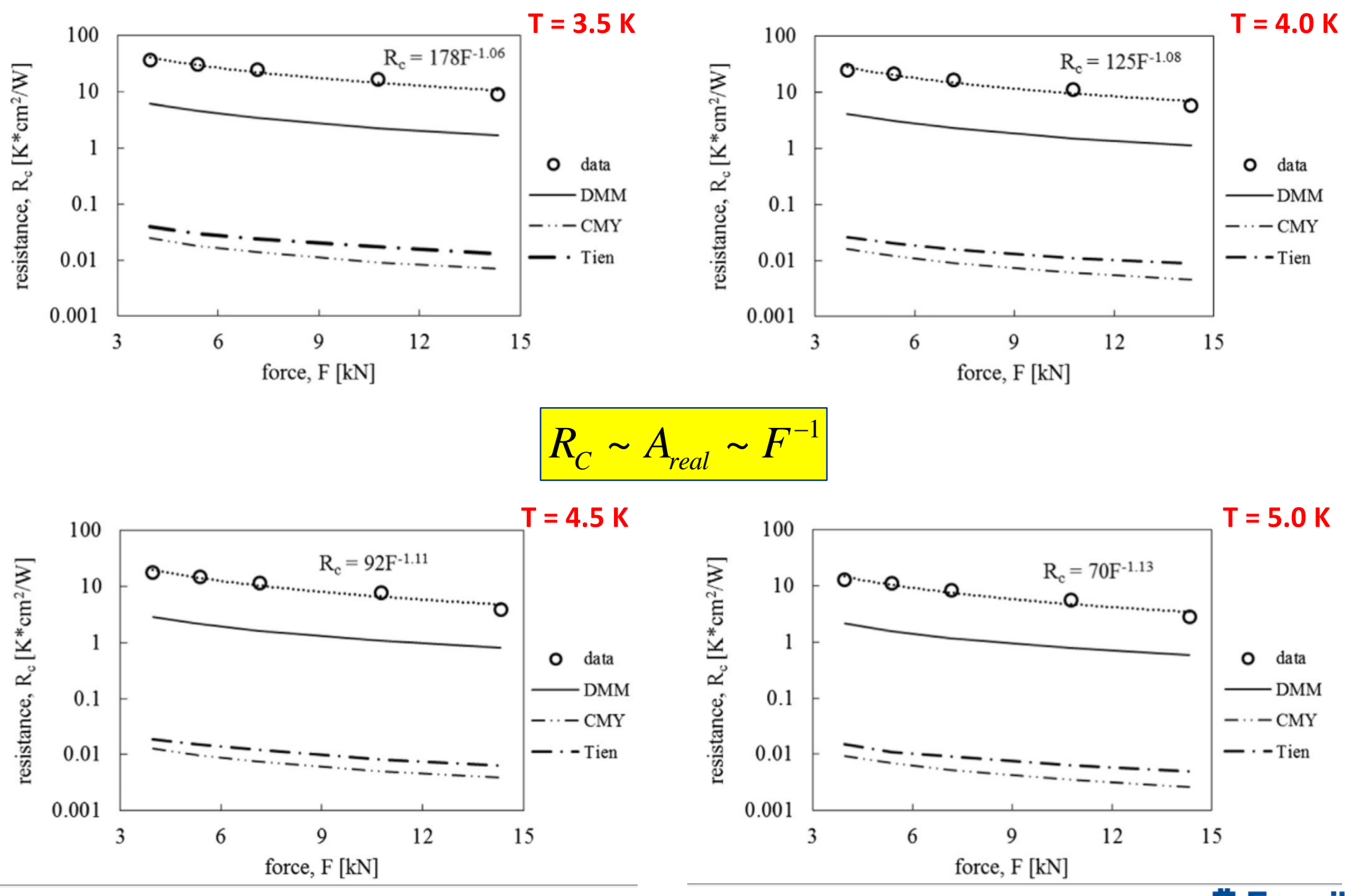


\section{Reducing thermal resistance of pressed contacts}

(Ref: Ekin)

\begin{tabular}{|l|l|l|}
\hline & Type of pressure contact & Common method for lowering thermal resistance \\
\hline 1 & Low pressure & $\begin{array}{l}\left.\text { Applying thermal grease (eg. Apiezon }{ }^{\top M} \mathrm{~N}\right) \text { or } \\
\text { varnish to each surface, thin layer of few microns }\end{array}$ \\
\hline 2 & $\begin{array}{l}\text { Moderate pressure (> yield } \\
\text { strength of pure indium } ~ 2 \mathrm{MPa})\end{array}$ & Pressing $2-5$ mils thick indium foil \\
\hline 3 & High force & $\begin{array}{l}\text { Gold plating surfaces, coating thickness }>\text { average } \\
\text { surface roughness }\end{array}$ \\
\hline
\end{tabular}

- For joints with grease, varnish, or indium ( $\mathrm{p}>2 \mathrm{MPa}) A_{\text {real }} \approx A_{\text {apparent }}$, so contact resistance will scale with apparent surface area (joint size).

- For dry or gold-plated joints $A_{\text {real }} \ll A_{\text {apparent }}$, so the contact resistance will scale with force and not with apparent surface area.

- Resistance mitigation:

- when large surface area is available, use grease with low pressure

- when space is limited, use gold-plated surfaces with a large force 


\section{Reducing resistance across pressed contacts}

Some methods of applying force

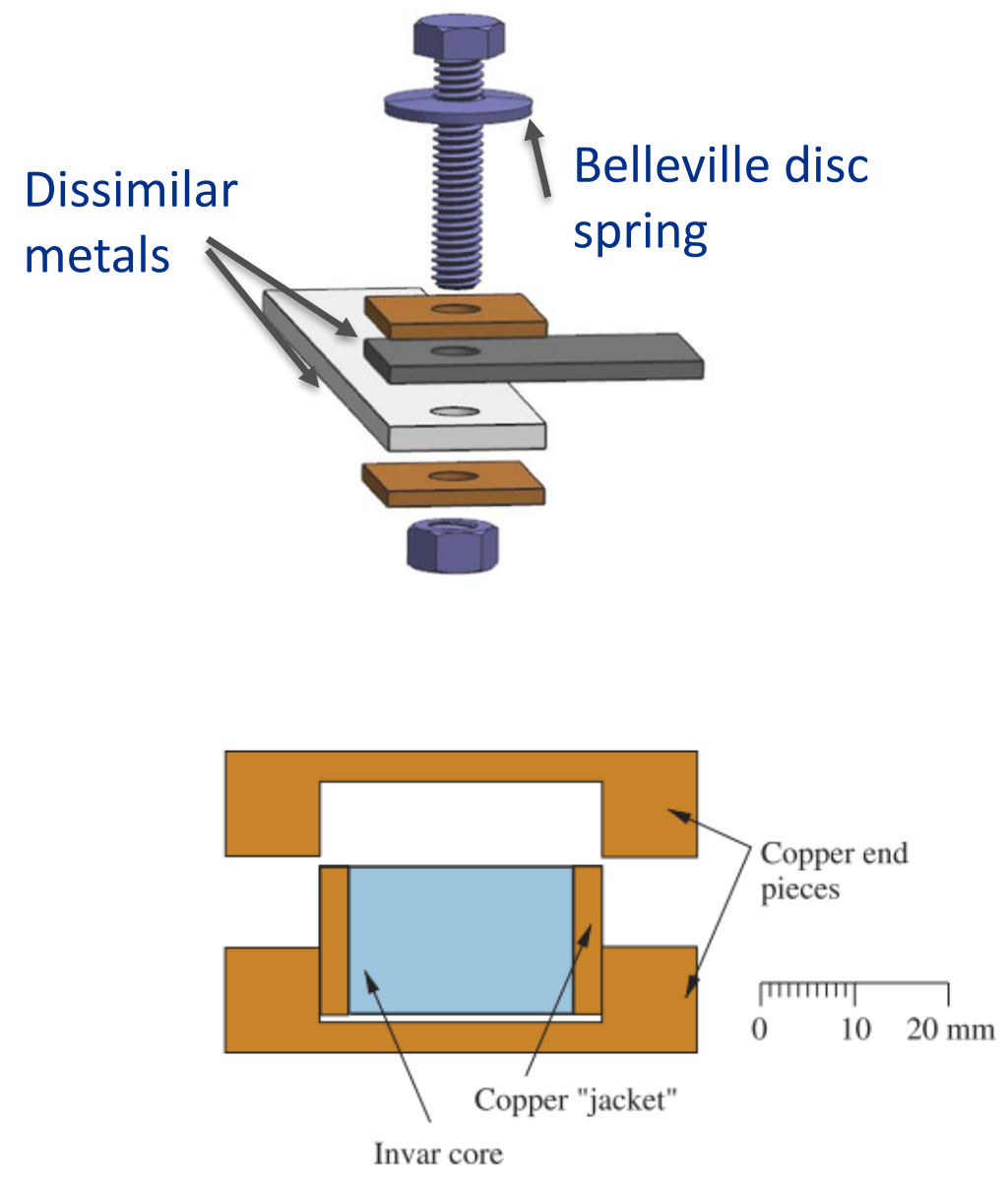

Bintley et al.: http://doi.org/10.1016/i.cryogenics.2007.04.004
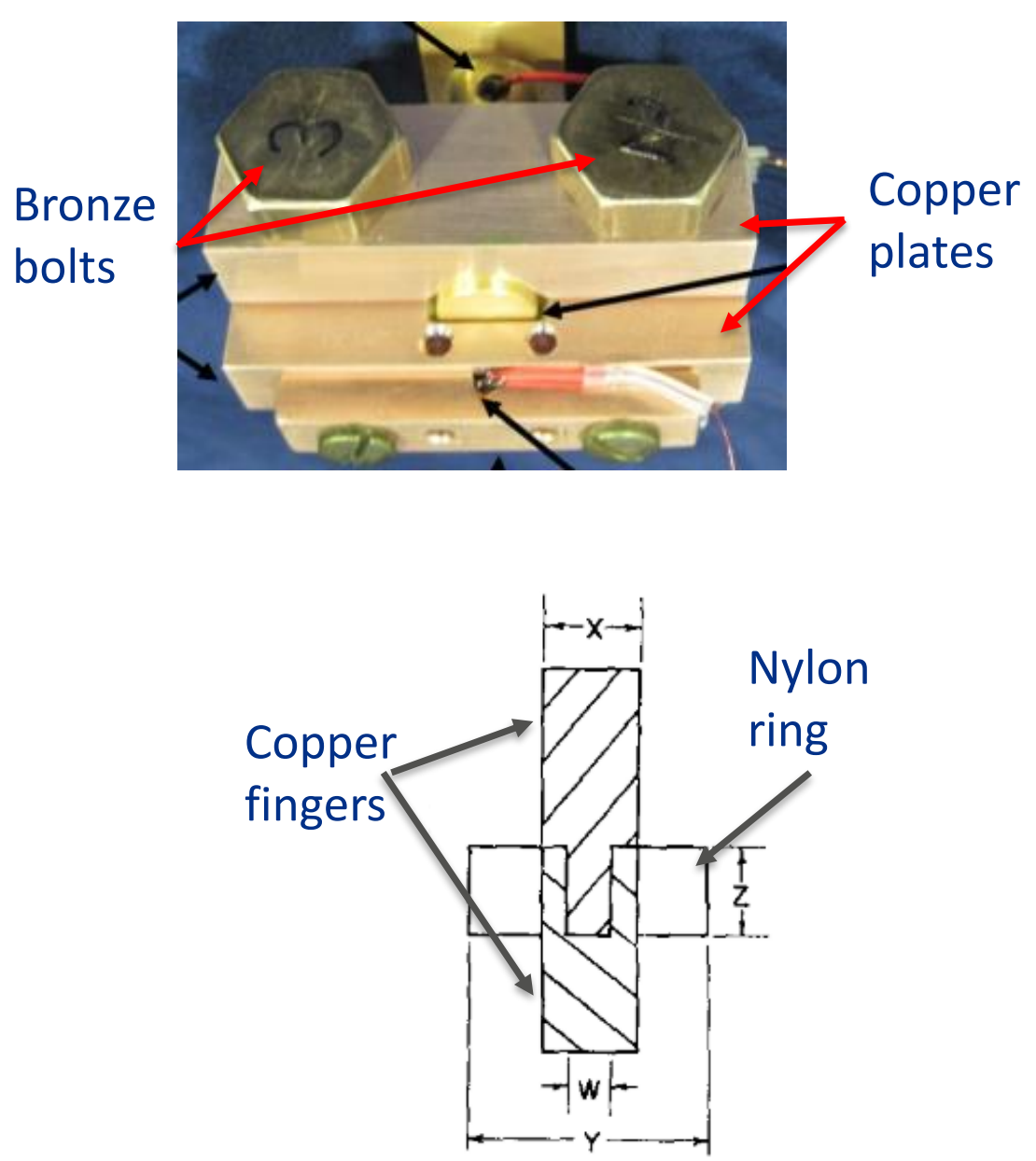

Boughton et al.: http://dx.doi.org/10.1063/1.1721058

军 Fermilab 


\section{Examples of data from literature}

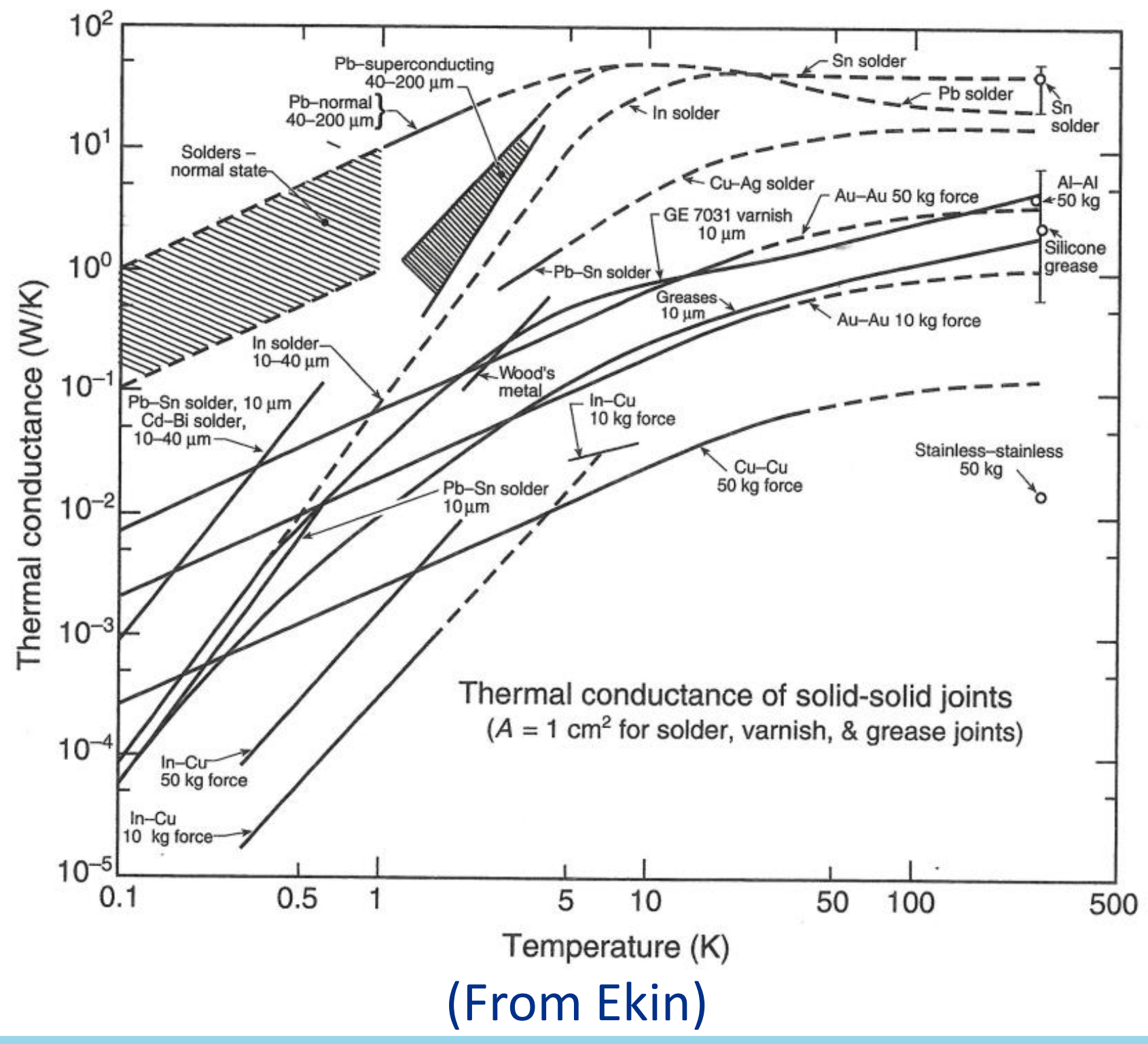




\section{Examples of data from literature}

Table II. Thermal Conductance of Metallic Contacts

\begin{tabular}{|c|c|c|c|c|c|c|}
\hline & Material & Contact & Pressure (MPa) & $\underline{h\left(w / \mathrm{cm}^{2} \mathrm{~K}\right)}$ & Temp. Range (K) & $\underline{\text { Ref }}$ \\
\hline 1. & Al-Al (alloy) & machined & torque $=20 \mathrm{Nm}$ & $0.075 \mathrm{~T}$ & $1.8-4.2$ & Wanner /13/ \\
\hline 2. & Al-Al alfoy & electropolished & torque $=20 \mathrm{Nm}$ & $3.6 \times 10^{-3} \mathrm{~T}^{2.3}$ & $1.8-4.2$ & \\
\hline 3. & $A 1-A 1$ alloy & Au plated & torque-20 $\mathrm{Nm}$ & $1.9 \times 10^{-3} \mathrm{~T}^{1.4}$ & $1.8-4.2$ & \\
\hline 4. & $\mathrm{Cu}-\mathrm{Cu}$ & machined & 2.8 & $4 \times 10^{-4} \mathrm{~T}^{2}$ & $1.8-4.2$ & Berman /8/ \\
\hline 5. & $\mathrm{Cu}-\mathrm{Cu}$ & machined & 14 & $1.67 \times 10^{-3} \mathrm{~T}^{2}$ & $1.8-4.2$ & \\
\hline 6. & $A u-A u$ & - & 5.6 & $0.05 \mathrm{~T}^{1.3}$ & $2-4$ & $\begin{array}{l}\text { Berman } \\
\text { Mate /7/ }\end{array}$ \\
\hline 7. & ss-ss (302) & polished & 21 & $0.014 \mathrm{~T}^{1.5 *}$ & $15-300$ & $\begin{array}{r}\text { Lyon } \\
\text { Parrish } / 14 /\end{array}$ \\
\hline 8. & SS-SS (302) & polished & 390 & $0.10 \mathrm{~T}^{1.5 *}$ & $15-300$ & • \\
\hline 9. & $\mathrm{Cu}-\mathrm{Cu}$ & machined & 7 & $0.13 \mathrm{~T}$ & $5-25$ & $\begin{array}{c}\text { Nilles } \\
\text { Van Sciver /15/ }\end{array}$ \\
\hline 10. & $\mathrm{Cu}-\mathrm{Cu}$ & in solder & -- & $7.5 \mathrm{~T}^{*}$ & $2-150$ & Radebaugh $/ 16 /$ \\
\hline 11. & $\mathrm{Cu}-\mathrm{Cu}$ & $\mathrm{Pb}$ solder & -- & $0.64 \mathrm{~T}^{2.8}$ & $1.5-4$ & $\begin{array}{l}\text { Challis } \\
\text { Cheeke /17/ }\end{array}$ \\
\hline 12. & $\mathrm{Cu}-\mathrm{Cu}$ & woods metal & -- & $0.018 T^{2.5}$ & $2-4$ & \\
\hline 13. & $\mathrm{Cu}-\mathrm{Cu}$ & $\mathrm{PbSn}$ solder & -- & $0.13 T^{1.6}$ & $2.5-4$ & Foster /18/ \\
\hline 14. & A1-A1 & SnPb foil & 26 & $0.02 T^{0.8 \star}$ & $10-300$ & $\begin{array}{l}\text { Friedman } \\
\text { Gasser } / 19 /\end{array}$ \\
\hline 15. & $\mathrm{Cu}-\mathrm{Al}$ & $\mathrm{SnPb}$ foll & 9 & $0.04 \mathrm{~T}^{\star}$ & $10-300$ & \\
\hline 16. & $\mathrm{Cu}-\mathrm{Cu}$ & SnPb Foil & 7 & $0.17 \mathrm{~T}^{*}$ & $10-300$ & \\
\hline
\end{tabular}

(From Van Sciver, Nilles, and Pfotenhauer) 


\section{Examples of data from literature}

Table III. Electrical Boundary Resistance at Low Temperatures $(\mathrm{T}=4.2 \mathrm{~K})$

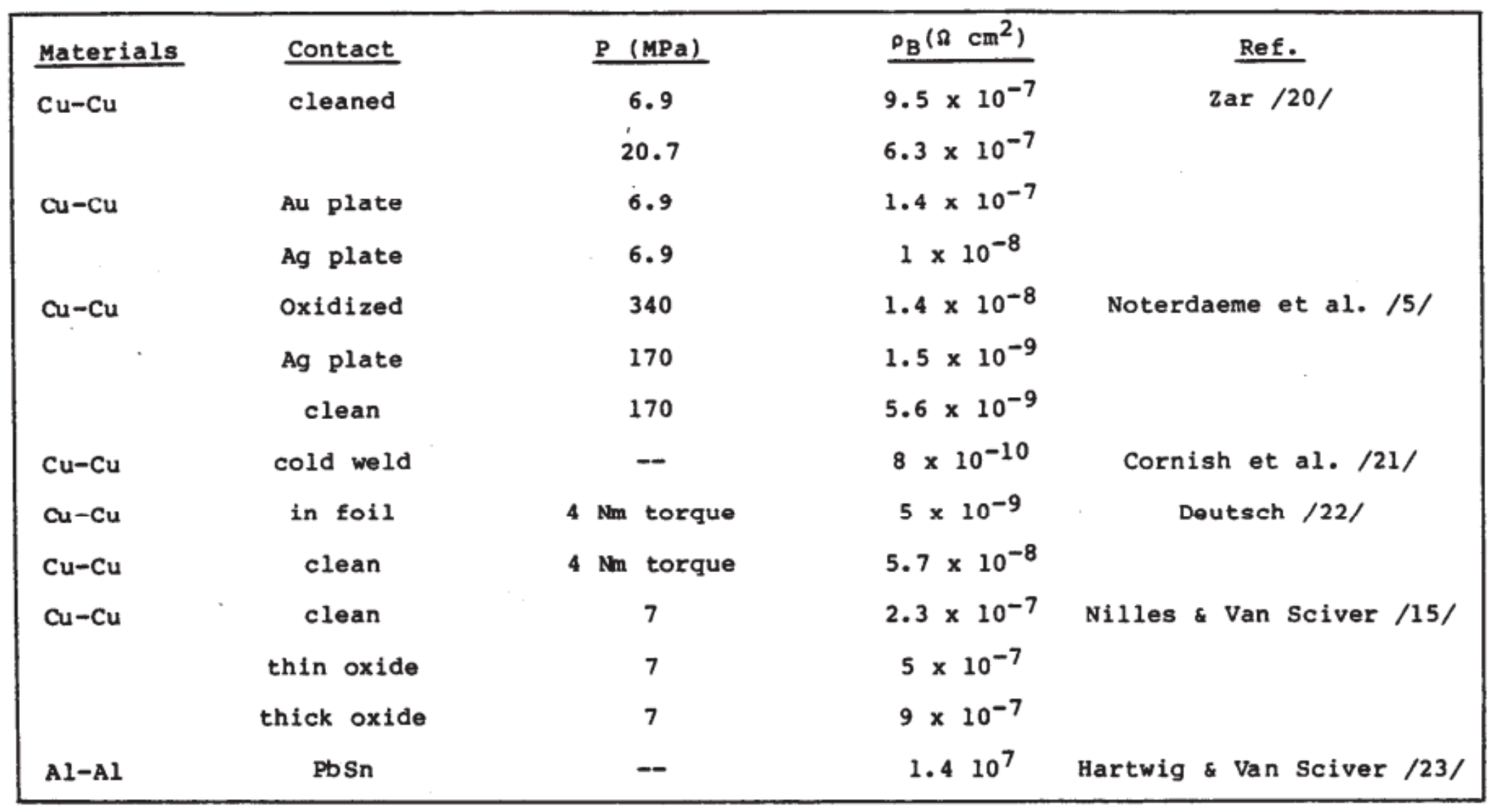

(From Van Sciver, Nilles, and Pfotenhauer) 


\section{Examples of data from literature}

Table I. Thermal Conductance of Insulating Contacts

\begin{tabular}{|c|c|c|c|c|c|c|}
\hline & Material & Contact & Pressure (MPA) & $\underline{h\left(W / \mathrm{cm}^{2} \mathrm{~K}\right)}$ & Temp range $(\mathrm{K})$ & Ref. \\
\hline 1. & In-sapphire & bonded & -- & $0.03 \mathrm{~T}^{3}$ & $1.4-2.1$ & $\begin{array}{c}\text { Neeper \& } \\
\text { Dillinger /6/ }\end{array}$ \\
\hline 2. & sapphire-sapphire & dry & 4 & $9 \times 10^{-6} \mathrm{~T}^{3}$ & $2-20$ & $\begin{array}{l}\text { Berman } 8 \\
\text { Mate } / 7 /\end{array}$ \\
\hline 3. & $\mathrm{Cu}$-diamond & dry & 4 & $2 \times 10^{-5} \mathrm{~T}^{3}$ & $1 \cdot 5-20$ & \\
\hline 4. & $\mathrm{Cu}-\mathrm{Teflon}-\mathrm{Cu}$ & $12 \mathrm{mil}$ foil & 4 & $1.8 \times 10^{-4} \mathrm{~T}^{2}$ & $2-5$ & Berman /8/ \\
\hline 5. & $\mathrm{Cu}-\mathrm{epoxy}-\mathrm{Cu}$ & bonded & -- & $0.09 \mathrm{~T}^{3}$ & $0.05-0.25$ & $\begin{array}{l}\text { Peterson } \& \\
\text { Anderson } / 2 /\end{array}$ \\
\hline 6. & Al-epoxy-Al & bonded & -- & $0.13 \mathrm{~T}^{3}$ & $0.05-0.25$ & \\
\hline 7. & $\mathrm{~Pb}$-epoxy-Pb & bonded & -- & $0.40 \mathrm{~T}^{3}$ & $0.05-0.25$ & \\
\hline 8. & $\mathrm{Be}$-epoxy-Be & bonded & - & $0.013 \mathrm{~T}^{3}$ & $0.05-0.25$ & \\
\hline 9. & Cu-LiF & $\mathrm{Ge-7031}$ & -- & $0.05 \mathrm{~T}^{3}$ & $0.4-1.3$ & $\begin{array}{c}\text { Ackerman } \& \\
\text { Anderson } / 9 /\end{array}$ \\
\hline 10. & $\mathrm{Cu}$-sapphire-Cu & dry & 0.1 & $1 \times 10^{-6} \mathrm{~T}^{3}$ & $1.5-4$ & $\begin{array}{c}\text { Yoo \& } \\
\text { Anderson } / 10 /\end{array}$ \\
\hline 11. & Cu-sapphire-Cu & $\mathrm{Al}_{2} \mathrm{O}_{3}$ & 0.1 & $2 \times 10^{-9} \mathrm{~T}^{3}$ & $0.8-3$ & \\
\hline 12. & $\mathrm{Cu}$-epoxy-Cu & bonded & -- & $0.16 \mathrm{~T}^{0.5}$ & $2-8$ & sumoto et al. /11 \\
\hline 13. & $\mathrm{Cu}-$ epoxy-Cu & bonded & - & $0.089 \mathrm{~T}^{1.9}$ & $1-4$ & Schmidt /12/ \\
\hline
\end{tabular}

(From Van Sciver, Nilles, and Pfotenhauer) 


\section{Examples of data from literature}

TABLE I. Electrical resistances at $4.2 \mathrm{~K}$ for the joints of various combinations of metals including other works. For reference, the resistances at room temperatures, the resistance ratios, contact area, diamcters of screws, and applied torques for fastening are listed only for this work.

\begin{tabular}{|c|c|c|c|c|c|c|c|}
\hline Metal & $\begin{array}{l}\text { Method of } \\
\text { contact }\end{array}$ & $\begin{array}{l}\text { Resistance } \\
\text { at } 4.2 \mathrm{X} \\
(\mu \Omega)\end{array}$ & $\begin{array}{l}\text { Resistance } \\
\text { at } 300 \mathrm{~K} \\
(\mu \Omega)\end{array}$ & $\begin{array}{l}\text { Resistance } \\
\text { ratio }\end{array}$ & $\begin{array}{l}\text { Contact } \\
\text { area } \\
\left(\mathrm{mm}^{2}\right)\end{array}$ & $\begin{array}{l}\text { Diameter } \\
\text { of screw } \\
(\mathrm{mm})\end{array}$ & $\begin{array}{l}\text { Torque } \\
\text { (N m) }\end{array}$ \\
\hline \multirow[t]{6}{*}{ Platinum and silver } & stainless-steel screw ${ }^{\mathrm{a}}$ & 0.005 & 0.87 & 174 & 126 & 5 & 12 \\
\hline & brass screw $w^{a}$ & 0.011 & 0.91 & 79 & 126 & 5 & 6 \\
\hline & stainless-steel screw ${ }^{\mathrm{a}}$ & 0.26 & 2.4 & 9.2 & 78 & 3 & 4 \\
\hline & brass screws" & 0.097 & 2.8 & 29 & 78 & 3 & 2 \\
\hline & brass screws (platinum & & & & & & \\
\hline & in fork-shaped silver) ${ }^{a}$ & 0.25 & 8.0 & 32 & 100 & 3 & 1 \\
\hline \multirow[t]{2}{*}{ Platinum and copper } & TIG weld ${ }^{a}$ & 17.5 & 310 & 18 & io & & \\
\hline & spot weld ${ }^{a}$ & 3.2 & 358 & 112 & 9 & & \\
\hline \multirow[t]{3}{*}{ Silver and silver } & EB welda & 0.018 & 0.91 & 50 & 16 & & \\
\hline & silver screw ${ }^{b}$ & 0.1 & & & & & \\
\hline & brass and stainless-steel screws ${ }^{c}$ & 0.03 & & & & & \\
\hline \multirow[t]{19}{*}{ Copper and copper } & silver solder $r^{d}$ & 17 & & & & & \\
\hline & silver solder ${ }^{e}$ & 0.17 & & & & & \\
\hline & gold plated and nylon squeeze $e^{e}$ & 0.3 & & & & & \\
\hline & indium solder ${ }^{f}$ & 2.45 & & & & & \\
\hline & epoxy plate and screw ${ }^{f}$ & 1 & & & & & \\
\hline & tapered screw & 1.3 & & & & & \\
\hline & gold plated and screw ${ }^{d}$ & 0.4 & & & & & \\
\hline & tapered screw ${ }^{f}$ & 0.1 & & & & & \\
\hline & screw ${ }^{\hat{t}}$ & 0.1 & & & & & \\
\hline & screws & 0.2 & & & & & \\
\hline & sanded and screws of brass & & & & & & \\
\hline & and stainless steel ${ }^{\mathrm{c}}$ & 0.13 & & & & & \\
\hline & chemically polished and screws of brass & & & & & & \\
\hline & and stainless steel ${ }^{c}$ & 0.06 & & & & & \\
\hline & nylon squeez $\mathrm{e}^{\mathrm{i}}$ & 0.04 & & & & & \\
\hline & gold plated and screws of brass & & & & & & \\
\hline & and stainless steel ${ }^{\circ}$ & 0.04 & & & & & \\
\hline & TIG weld untreated ${ }^{\mathrm{d}}$ & 0.034 & & & & & \\
\hline & TIG weid annealed ${ }^{\mathrm{d}}$ & 0.013 & & & & & \\
\hline
\end{tabular}

(From Mamiya et al.) 


\section{Examples of data from literature}

Table 1. Summary of Thermal Contact Literature

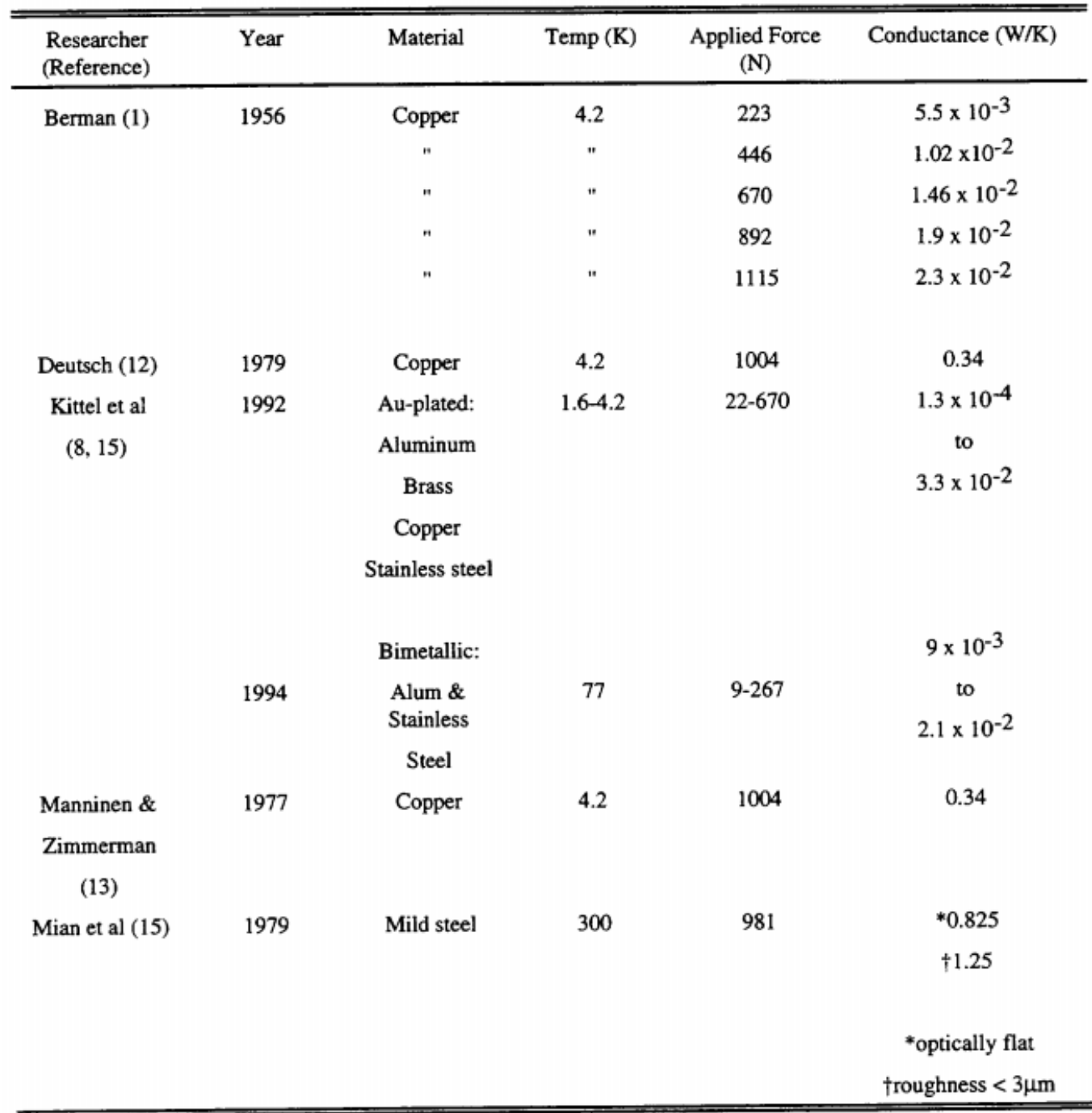

(From Salerno and Kittel) 


\section{Examples of data from literature}

Table 1. Summary of Thermal Contact Literature (continued)

\begin{tabular}{|c|c|c|c|c|c|}
\hline $\begin{array}{l}\text { Researcher } \\
\text { (Reference) }\end{array}$ & Year & Material & Temp (K) & $\begin{array}{l}\text { Applied Force } \\
\text { (N) }\end{array}$ & Conductance (W/K) \\
\hline \multirow{6}{*}{$\begin{array}{l}\text { Nilles and Van } \\
\text { Sciver (11) }\end{array}$} & \multirow[t]{6}{*}{1988} & \multirow{3}{*}{$\begin{array}{l}\text { Copper } \\
\text {-oxidation } \\
\text { treatment }\end{array}$} & \multirow[t]{6}{*}{ 4-290 } & \multirow[t]{6}{*}{129} & $4 \times 10^{-3}$ \\
\hline & & & & & $1.4 \times 10^{-2}$ \\
\hline & & & & & $2.0 \times 10^{-2}$ \\
\hline & & -normal & & & $80 \times 10^{-2}$ \\
\hline & & & & & $1.3 \times 10^{-1}$ \\
\hline & & & & & $1.4 \times 10^{-1}$ \\
\hline \multirow{3}{*}{$\begin{array}{l}\text { Radebaugh et al } \\
\text { (17) }\end{array}$} & \multirow[t]{3}{*}{1977} & Copper & 4.2 & 490 & $10^{-2}$ \\
\hline & & Polished Ag & 4.2 & 490 & 1.1 \\
\hline & & Stainless Stl & 300 & 490 & $10^{-2}$ \\
\hline \multirow{4}{*}{$\begin{array}{c}\text { Salerno et al } \\
(4,5,6,7)\end{array}$} & 1984 & Aluminum & \multirow[t]{4}{*}{$1.6-4.2$} & \multirow[t]{4}{*}{$22-670$} & $1 \times 10^{-4}$ \\
\hline & 1985 & Brass & & & to \\
\hline & 1986 & Copper & & & $2.0 \times 10^{-2}$ \\
\hline & & Stainless Stl & & & \\
\hline \multirow{8}{*}{$\begin{array}{c}\text { Salerno et al } \\
(9,10)\end{array}$} & \multirow[t]{6}{*}{1993} & Augmented: & \multirow[t]{6}{*}{$1.6-4.2$} & \multirow[t]{6}{*}{$22-670$} & $3.6 \times 10^{-5}$ \\
\hline & & Aluminum & & & to \\
\hline & & Brass & & & $1.0 \times 10^{-2}$ (Au-plated \\
\hline & & Copper & & & Washer) \\
\hline & & Stainless Steel & & & \\
\hline & & & & & $5.0 \times 10^{-4}$ \\
\hline & \multirow{2}{*}{1994} & & & & to \\
\hline & & & & & $0.28(\mathrm{In}, \mathrm{Ap})$ \\
\hline $\begin{array}{l}\text { Suomi et al } \\
\text { (18) }\end{array}$ & 1968 & Copper & $0.02-0.2$ & $?$ & $10^{-2}$ \\
\hline \multirow{2}{*}{$\begin{array}{l}\text { Thomas \& } \\
\text { Probert (19) }\end{array}$} & \multirow[t]{2}{*}{1970} & \multirow[t]{2}{*}{ Stainless Steel } & \multirow[t]{2}{*}{$88-95$} & 446 & 0.36 \\
\hline & & & & 892 & 0.5 \\
\hline \multirow[t]{4}{*}{ Wanner (20) } & \multirow[t]{4}{*}{1981} & \multirow[t]{4}{*}{ Aluminum } & \multirow[t]{4}{*}{$1-4$} & 4683 & $* * 0.2$ \\
\hline & & & & 9366 & $* * 0.6$ \\
\hline & & & & 12488 & $* * 1.5$ \\
\hline & & & & & $\boldsymbol{*}_{\text {at }} 4.2 \mathrm{~K}$ \\
\hline
\end{tabular}

(From Salerno and Kittel) 


\section{Useful references}

Overview of constriction resistance models

- Madhusudhana: https://www.springer.com/us/book/9783319012759

- Lambert and Fletcher: https://dx.doi.org/10.2514/2.6221

- Bahrami et al.: http://dx.doi.org/10.1115/1.2110231

Overview of boundary resistance models

- Little: https://doi.org/10.1139/p59-037

- Swartz and Pohl: https://doi.org/10.1103/RevModPhys.61.605

- Gundrum et al.: https://doi.org/10.1103/PhysRevB.72.245426

- Prasher and Phelan: https://doi.org/10.1063/1.2353704

Data at cryogenic temperatures (reviews)

- Salerno and Kittel: NASA NTRS 19970026086

- Mamiya et al.: https://doi.org/10.1063/1.1139684

- Van Sciver, Nilles, Pfotenhauer: Proc. SCW 1984

- Gmelin et al.: https://doi.org/10.1088/0022-3727/32/6/004

- Ekin: http://dx.doi.org/10.1093/acprof:oso/9780198570547.001.0001

- Dhuley: 
"You are working on a very complex problem from both a mechanical and a thermal perspective. There are no simple solutions or models."

Michael M. Yovanovich 
This document has been authored by Fermi Research Alliance, LLC under Contract No. DE-AC02-07CH11359 with the U.S. Department of Energy, Office of Science, Office of High Energy Physics. 